\section{Research Square}

Preprints are preliminary reports that have not undergone peer review.

They should not be considered conclusive, used to inform clinical practice, or referenced by the media as validated information.

\title{
Risk Factors for Late Linkage to Care and Delayed Antiretroviral Therapy Initiation Amongst HIV Infected Adults in Sub-saharan Africa: a Systematic Review and Meta-analyses
}

\author{
Terefe Gone Fuge ( $\nabla$ terefegone@gmail.com ) \\ Flinders University of South Australia: Flinders University \\ George Tsourtos \\ Flinders University of South Australia: Flinders University \\ Emma Miller \\ Flinders University of South Australia: Flinders University
}

\section{Research Article}

Keywords: HIV, linkage to care, antiretroviral therapy initiation, factors, adults, sub-Saharan Africa

Posted Date: January 27th, 2022

DOI: https://doi.org/10.21203/rs.3.rs-840708/v1

License: (c) (1) This work is licensed under a Creative Commons Attribution 4.0 International License. Read Full License 


\section{Abstract}

Background: Late linkage to care and delay in antiretroviral therapy (ART) initiation threaten the clinical and public health benefits of ART such as: preventing acquired immunodeficiency syndrome (AIDS) and non-AIDS related morbidities and mortality, as well as reducing new infections. The prevalence of both of these poor care outcomes remains high in sub-Saharan African (SSA) countries. Quantitative synthesises of the existing data are lacking, which would help ascertain the best evidence-based interventions. This review aimed to systematically synthesise the available literature on factors affecting linkage to care and ART initiation amongst HIV infected adults in SSA.

Methods: Systematic searches were undertaken of the following databases: Emcare, Medline, PubMed and Web of Science. In our review, we included observational studies that analysed factors affecting linkage to HIV care and ART initiation amongst adults (age $\geq 19$ years) in SSA, and were published between January 1, 2015 and June 1, 2021. All included studies were assessed for risk of bias using the Effective Public Health Practice Project (EPHPP) Quality Assessment Tool for Quantitative Studies. RevMan-5 software was used to conduct meta-analyses and MantelHaenszel statistics to pool outcomes with $95 \%$ confidence interval and $<0.05$ level of significance. The review protocol has been published at the International Prospective Register of Systematic Reviews (PROSPERO; Number: CRD42021264398).

Results: Forty-six studies were included in the systematic review, of which 18 fulfilled requirements for meta-analysis. Health care delivery, psychosocial, behavioural and sociodemographic factors were identified as determinants of late linkage to care and delay in ART initiation. The meta-analyses showed that people of a younger age group (<35 years) were $29 \%$ (OR: $\left.0.71 ; 95 \% \mathrm{Cl}: 0.55-0.91, \mathrm{I}^{2}=74 \%\right)$ and $45 \%$ (OR: $0.55 ; 95 \% \mathrm{Cl}$ : $0.49-0.63, I^{2}=0 \%$ ) less likely to be linked to care and initiate ART respectively compared to people of an older age group ( $\geq 35$ years). Employed people and people who travelled for more than an hour to reach a clinic were more than 1.3 (OR: 1.32; 95\%Cl: 1.14-1.52, $\left.\mathrm{I}^{2}=14 \%\right)$ and 1.2 (OR: 1.27; $95 \% \mathrm{Cl}: 1.15-1.39, \mathrm{I}^{2}=57 \%$ ) times more likely to be presented late for care, respectively. The likelihood of linkage to care decreased by $26 \%$ (OR: 0.74 ; $95 \% \mathrm{Cl}: 0.62-0.87, \mathrm{I}^{2}=25 \%$ ) for people who were unable to disclose their HIV status and 50\% (OR: 0.50; $95 \% \mathrm{Cl}: 0.42-0.60, \mathrm{I}^{2}=0 \%$ ) for those who had a baseline CD 4 count $>350$ cells $/ \mathrm{mm}^{3}$ compared to CD 4 count $\leq 350$ cells $/ \mathrm{mm}^{3}$, but increased by $65 \%$ (OR: $\left.1.65 ; 95 \% \mathrm{Cl}: 1.16-2.34, \mathrm{I}^{2}=0 \%\right)$ for those who were diagnosed through health facility-based testing approaches compared to community-based approaches.

Conclusion: This systematic review and meta-analyses identified a range of risk factors for late linkage to care and delayed ART initiation amongst HIV infected adults in SSA including: health service delivery, psychosocial, behavioural and sociodemographic circumstances. We recommend implementation of patient-centred intervention approaches to alleviate these barriers.

\section{Background}

Antiretroviral therapy (ART) has transformed HIV infection from a fatal to a potentially manageable chronic disease and has significantly elongated the life expectancy of people living with HIV (PLWH) [1]. In addition to its effect in preventing acquired immunodeficiency syndrome (AIDS) and nonAIDS related comorbidities and mortality [2, 3], early initiation of ART significantly reduces new HIV infections by suppressing viral concentration in PLWH $[4,5]$.

While international guidelines recommend linkage to care and initiating ART at the time of diagnosis (a strategy known as "Test and Treat") [6], PLWH in sub-Saharan African (SSA) countries often commence ART at advanced stages of infection (at CD 4 count $<200 \mathrm{cells} / \mathrm{mm}^{3}$ and/or World Health organization (WHO) clinical sage III/IV) [7-10]. High prevalence of late linkage to care [7, 11, 12] and ART initiation [10, 13, 14] has been reported in many SSA countries.

Individual studies reported various structural, psychosocial and behavioural risk factors for late linkage to HIV care and ART initiation amongst PLWH in SSA. Among structural factors, barriers to health care delivery, such as distance to a health care facility, have been commonly reported $[8,15,16]$. Psychosocial circumstances, including the presence of social support and an ability to disclose one's HIV status, have been found to affect linkage to care and ART initiation [17, 18]. In addition, behavioural patterns related to perceptions of the health benefits of early ART [19-22], as well as an acceptance of HIV positive status, have been strongly linked to the level of the patients' engagement in care and ART initiation [10, 19, 23]. Sociodemographic characteristics, such as patient age and gender, have also been frequently reported to be associated with late linkage to care and delays in ART initiation [17, 20, 24-27].

Across published studies, there are variations in definitions of HIV care-related health outcomes as well as contextual differences associated with the risk factors for late linkage to care and delayed ART initiation. The resulting lack of unequivocal evidence has substantially impeded successful implementation of available interventions as well as the development of novel strategies for improving care linkage and ART initiation [28, 29]. Whilst systematic reviews have been conducted on this topic in SSA [30-32], a few have quantitatively focussed on factors of various levels relating to late linkage to care or delays in ART initiation. Further, most were conducted before the endorsement of the "Test and Treat" strategy [6], underscoring the need for more inclusive and up to date information. Our review aimed to systematically synthesise the available evidence on barriers to care linkage and ART initiation amongst adult PLWH in SSA in order to suggest contextually tailored intervention strategies.

\section{Methods}


This review was reported based on the Preferred Reporting Items for Systematic Reviews and Meta-Analyses guidelines (PRISMA) [33] (see Additional file 1). The review protocol has been published at the International Prospective Register of Systematic Reviews (PROSPERO; Number: CRD42021264398) [34] (see Additional file 2).

\section{Eligibility criteria}

Studies: We reviewed observational studies analysing factors affecting linkage to HIV care and/or ART initiation in the target population. Qualitative and intervention-based studies were not considered as the aim of the review was to quantify risk factors in a natural setting.

Participants: The review included HIV-infected adults (as WHO [6] defines: $\geq 19$ years of age) in SSA. Studies conducted on specialised population groups that may have a particular risk for the health outcomes under investigation such as: sex workers, men having sex with men, pregnant women, tuberculosis (TB) patients and serodiscordant couples were excluded.

Exposures: Structural factors pertaining to healthcare access and other healthcare delivery barriers (e.g. distance to a healthcare facility), psychosocial and personal determinants of late presentation for HIV care and ART initiation (such as the influence of social support, status disclosure, and perceptions of early treatment initiation) were exposures of interest in the review. We also assessed the influence of sociodemographic factors such as age, gender, marital status, and other characteristics.

Comparators: While no restriction was made based on whether a study had used comparators, individuals without an exposure of interest were considered as the control group when comparisons were made.

Outcome measures: Rates of linkage to HIV care and ART initiation over a certain period of time (as defined by individual studies) were considered the main outcomes of the review. No restriction was made on the inclusion of studies based on the definition of the outcomes.

\section{Information sources and search strategy}

We conducted systematic searches in databases including MEDLINE, PubMed, Web of Science and Emcare. The search strategy was designed using the concepts 'HIV/AIDS', 'ART' and 'Linkage to HIV Care or Initiation of ART' and names of countries in SSA. Terms related to the concepts were used and combined with the MEDLINE filter. The search strategy for MEDLINE was: HIV or Human Immunodeficiency virus or AIDS or Acquired Immunodeficiency Syndrome or (HIV or AIDS or HIV-AIDS or Acquired Immunodeficiency Syndrome or Human immunodeficiency virus).tw,kf. and ART or Antiretroviral Therapy or Highly Active antiretroviral therapy and "linkage to care" or "presentation to care" or start* or initiate* or (antiretroviral* or anti-retroviral* or HAART or ART or anti-hiv).tw,kf. and (Angola or Benin or Botswana or Burkina Faso or Burundi or Cape Verde or Cameroon or Central African Republic or Chad or Comoros or Democratic Republic of the Congo or Congo or Cote D'ivoire or Equatorial Guinea or Eritrea or Eswatini or Ethiopia or Gabon or Gambia or Ghana or Guinea or Guinea-Bissau or Kenya or Lesotho or Liberia or Madagascar or Malawi or Mali or Mauritania or Mauritius or Mozambique or Namibia or Niger or Nigeria or Rwanda or "Sao Tome and Principe" or Senegal or Seychelles or Sierra Leone or Somalia or South Africa or South Sudan or Sudan or Tanzania or Togo or Uganda or Zambia or Zimbabwe). We adapted the search terms to use with other bibliographic databases along with database-specific filters. Studies involving adults ( $\geq 19$ years), published in English language since 2015 and indexed up to June 1, 2021 were retrieved. We selected a period from 2015 for the review as this was the time when WHO announced the new "Test and Treat" Strategy [6].

\section{Study selection and risk of bias assessment}

One review author (TGF) performed screening of articles for their relevance to the review question with titles and abstracts. After removal of duplicate and irrelevant articles, the same author performed a full text review on the retrieved articles based on a protocol published in advance [34]. Three independent assessors (including the first author of the review -TGF) conducted a quality assessment (risk of bias) of the retrieved articles using the Effective Public Health Practice Project (EPHPP) Quality Assessment Tool for Quantitative Studies (see Additional file 3). The quality assessment process considered the following characteristics: representativeness of participants (selection bias), appropriateness of the study design to answer study objectives, control of potential confounders, validity and reliability of data collection methods and completeness of outcome data (withdrawals and dropouts). Disagreements between the assessors were resolved by discussion and decided by a final independent assessment where required.

\section{Data abstraction}

We used a format adapted from the Cochrane Systematic Review Checklist for Data Collection to extract data (see Additional file 4). Separate data extraction formats were used for linkage to care and ART initiation. The data extraction form included information regarding author, year, country, population, method, measurements, exposures, results, and conclusions. We contacted corresponding authors of seven primary studies for additional data regarding an exposure of interest versus the outcomes

\section{Data synthesis}

We provided a narrative review of the results across studies regarding exposures and outcomes. We conducted a meta-analysis when at least two studies measured the same exposure and outcome, using comparable definitions. A Fixed-Effect model was used when the number of studies was small $(n<5)$ and when a substantial difference was observed between sample sizes, which could limit the generalisability of the findings beyond the included studies [35, 36]; otherwise, a Random-Effects Model was applied to pool the outcomes with odds ratios and to calculate $95 \%$ confidence

Page 3/28 
intervals. Heterogeneity between studies in effect measures was determined using $\mathrm{Chi}^{2}$ test and $\mathrm{I}^{2}$ statistic, and an $\mathrm{I}^{2}$ value of $75 \%$ was considered as high heterogeneity [37]. We used RevMan-5 software [38] to calculate pooled odds ratios by applying Mantel-Haenszel statistics for each outcome and a forest plot to present the results.

\section{Results}

The electronic literature search identified 2597 articles, of which 451 were duplicates and 2064 were irrelevant to the review question (based on the title and abstract appraisal). An additional 36 articles were removed after the full text review that was based on the eligibility criteria (i.e. studies conducted on ineligible populations, qualitative studies, intervention studies, review articles or articles lacking the desired outcomes: not reporting on linkage to care or ART initiation). Among the remaining 46 studies that were included in the review, 18 met the criteria for meta-analysis. Figure 1 depicts the selection process and number of articles excluded and retrieved at each stage.

\section{Study characteristics}

The characteristics of the 46 included studies are presented in Tables 1 and 2. Almost half (46\%) of the studies were from eastern Africa: nine from Ethiopia, five from Kenya, three from Tanzania and two each from Uganda and Rwanda. Those from southern Africa (South Africa, Malawi, Mozambique and Zimbabwe) accounted for $39 \%$ of the review articles. Six studies were from western and central Africa: two from Cameroon, and one each from Guinea-Bissau, Nigeria, Senegal and Cape Verde. One study used a clinic-based cohort across four countries (Uganda, Kenya, Tanzania and Nigeria). More than half (52\%) of the studies used a (mostly retrospective) cohort design $[9,11,13,14,17,19,20,27,39-53]$ while 17 studies employed a cross-sectional design [7, 8, 10, 15, 23, 51, 54-64]. Two studies applied observational cluster randomized [65] and nonrandomized trials [66], and the remaining three employed a case-control design [67-69]. Twenty-one studies reported on linkage to HIV care [7, 8, 11, $15,17,19,27,44,45,47,48,50,57-61,67-70]$ (Table 1), seventeen on ART initiation $[9,10,13,14,39-43,51-53,55,62-65]$ and the rest eight reported both outcomes $[12,20,23,46,49,54,56,66]$ (Table 2$)$.

\section{Methodological quality}

Almost three-quarters (72\%) of the studies were assessed as 'moderate' or 'strong' quality in regard to ensuring the representativeness of participants, and $61 \%$ of them were scored as 'moderate' regarding the appropriateness of the study design. Most studies (70\%) were assessed as having a strong performance in controlling confounders (i.e., controlled at least $80 \%$ of relevant confounders). Only ten (22\%) studies described the validity and/or reliability of the data collection tools, of which three studies were assessed as 'strong' in this regard. Similarly, nine (20\%) studies considered the risk of drop-out and withdrawal, and three of them reported a follow-up rate of more than $80 \%$ (a strong performance). This criterion was inapplicable in most (67\%) of the studies. Overall, one study was assessed as 'strong' and 24 other studies (52\%) were assessed as having a moderately strong methodological quality on the EPHPP tool (see Additional file 5).

\section{Measurements}

In most studies, the rate of linkage to care was determined based on the time since diagnosis $[12,17,19,20,23,45-47,49,50,54,56-58,60,66,70]$, and late presentation for care was defined as engagement in care at CD4 count $<350 \mathrm{cells} / \mathrm{mm}^{3}$ and/or WHO clinical stage III/IV [11, $\left.44,61,67,68\right]$. Five studies considered care engagement at CD 4 count $<200$ cells $/ \mathrm{mm}^{3}$ as late linkage to care $[8,11,48,59,69]$ and one study at CD4 count $\leq 100$ cells $/ \mathrm{mm}^{3}$ [15]. One other study defined late linkage to care as diagnosis at CD4 count of $\leq 500 \mathrm{cells} / \mathrm{mm}^{3}$ and/or any of the WHO clinical stages [7]. Interestingly, a study by Maheu-Giroux et al [27] in South Africa determined linkage to care by estimating the length of time between HIV infection and engagement in care.

Twelve of 25 ART initiation studies measured the rate of ART initiation after engagement in care $[10,12,13,23,39,40,42,46,51,54,56,65]$ with two of these defining delayed ART initiation as commencing ART at CD4 count $<150$ cells $/ \mathrm{mm}^{3}$ or at WHO clinical stage IV [10, 51]. One study defined delayed ART initiation as having a CD4 count below or at 200 cells $/ \mathrm{mm}^{3}$ and/or AIDS defining illness at treatment start [62]. The remaining 12 studies measured the length of time between ART eligibility (based on guidelines available at a particular period of time) and ART initiation [9, 14, 20, $41,43,49,55]$ or between HIV diagnosis and ART initiation including same day treatment (i.e. initiating treatment on the date of diagnosis) [52, 53, $63,64,66]$. In this review, we used more inclusive definitions for both outcomes. Accordingly, we defined late linkage to HIV care as engagement in care at CD 4 count $<350$ cells $/ \mathrm{mm}^{3}$ or at WHO clinical stage III/IV, and delayed ART initiation as starting HIV medication at CD4 count $<350$ cells $/ \mathrm{mm}^{3}$ or WHO clinical stage III/IV.

\section{Linkage to HIV care}

Summary of care linkage results are presented in Table 1. Maheu-Giroux et al [27] identified a median time to care linkage after HIV infection of 4.9 years. Among studies that investigated the rate of linkage to care since diagnosis, the rate was within three months of diagnosis [12, 49, 50, 56, 58, $66,70]$. The rate ranges from $24 \%$ in Tanzania [12] to $93 \%$ in South Africa [50]. Two Tanzanian studies estimated the rate of linkage to care within six months of diagnosis and reported a rate of more than $70 \%[19,45]$. Contradictory results were reported by two studies, in Ethiopia [20] and South Africa [17]; while the former study reported care engagement in 75\% of PLWH within one week of diagnosis, only $46 \%$ were linked to care within 12 months in the latter. However, a more recent study in South Africa reported a rate of 55\% within 12-weeks of diagnosis [60].

Page $4 / 28$ 
Table 1

Characteristics of studies investigating linkage to HIV care

\begin{tabular}{|c|c|c|c|c|c|c|}
\hline Author & Country & Population & $\begin{array}{l}\text { Study } \\
\text { Design }\end{array}$ & Measurement & $\begin{array}{l}\text { Types of } \\
\text { exposures }\end{array}$ & Findings \\
\hline $\begin{array}{l}\text { Dorward et } \\
\text { al [17] }\end{array}$ & South Africa & $\begin{array}{l}2398 \text { HIV } \\
\text { infected } \\
\text { individuals }\end{array}$ & $\begin{array}{l}\text { Cohort } \\
\text { (2012- } \\
2015)\end{array}$ & $\begin{array}{l}\text { Length of time } \\
\text { from the date of } \\
\text { testing to linkage to } \\
\text { care. }\end{array}$ & $\begin{array}{l}\text { Age, gender, } \\
\text { type of testing } \\
\text { district, } \\
\text { employment, } \\
\text { level of } \\
\text { education, } \\
\text { household } \\
\text { income, } \\
\text { distance to the } \\
\text { referral clinic, } \\
\text { CD4 count at } \\
\text { linkage, } \\
\text { relationship } \\
\text { status, HIV } \\
\text { status } \\
\text { disclosure }\end{array}$ & $\begin{array}{l}46 \% \text { of } \\
\text { participants } \\
\text { linked to care } \\
\text { within } \\
\text { 365days of } \\
\text { HIV testing; } \\
\text { median time to } \\
\text { linkage: } \\
\text { 30days. }\end{array}$ \\
\hline
\end{tabular}

Conclusions

Younger age $(\leq 30$

years) (AHR: 0.58; 95\%

Cl: $0.50-0.68)$, male gender (AHR: 0.86; 95\%

Cl: $0.76-0.98)$, having

diagnosis in the more

urban district (AHR:

0.82 ; $95 \% \mathrm{Cl}: 0.73-$

.93), being employed

(AHR: $0.81 ; 95 \% \mathrm{Cl}$ :

$0.72-0.92$ ) were

associated with

decreased hazard of

inkage-to-care; non-

disclosure of HIV

status had more

impact on linkage to

care in men (AHR: 0.53;

95\% Cl: 0.42-0.66)

than women (AHR:

0.70 ; $95 \%$ Cl: $0.60-$

$0.82)$.

\begin{tabular}{|c|c|c|c|c|c|c|}
\hline $\begin{array}{l}\text { van der } \\
\text { Kop et al } \\
\text { [8] }\end{array}$ & Kenya & $\begin{array}{l}755 \text { HIV } \\
\text { infected } \\
\text { individuals }\end{array}$ & $\begin{array}{l}\text { Cross- } \\
\text { sectional }\end{array}$ & $\begin{array}{l}\text { Late presentation } \\
\text { for care defined as } \\
\text { first presentation } \\
\text { with a CD } 4 \text { count of } \\
<200 \text { cells } / \mathrm{mm}^{3} \text { or } \\
\text { at WHO stage IV. }\end{array}$ & $\begin{array}{l}\text { Age, gender, } \\
\text { education, } \\
\text { travel time to a } \\
\text { clinic, alcohol } \\
\text { use, illicit drug } \\
\text { use }\end{array}$ & $\begin{array}{l}\text { Median time to } \\
\text { presentation } \\
\text { after first HIV } \\
\text { testing: } 22 \\
\text { days in those } \\
\text { with advanced } \\
\text { HIV; } 19 \text { days in } \\
\text { those without } \\
\text { advanced HIV. }\end{array}$ \\
\hline
\end{tabular}

Age $\geq 30$ years was associated with presenting to care with advanced HIV

compared to age $<30$ years (AOR: 1.72; 95\% Cl: 1.45-2.03) advanced HIV.

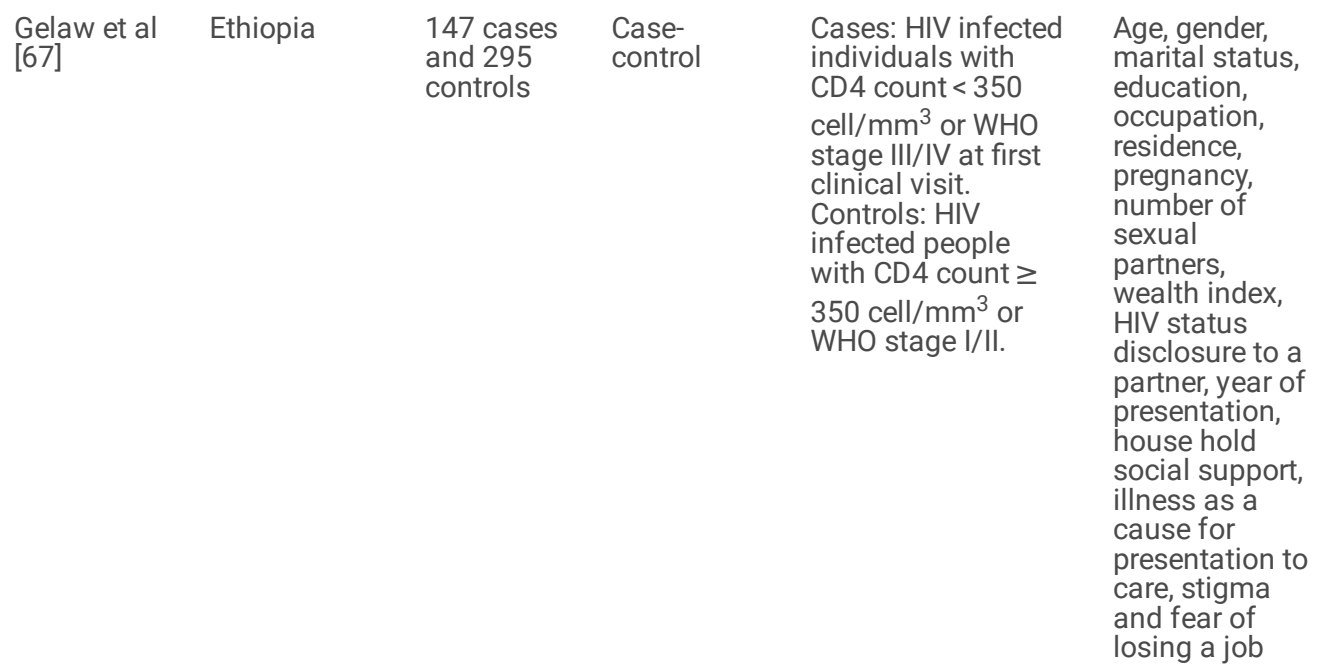

AHR: Adjusted hazards ratio; AOR: Adjusted odds ratio; APRR: Adjusted prevalence risk ratio; ART: Antiretroviral therapy; ARV: Antiretroviral; ASHR Adjusted sub-hazard ratio; CBSS: Community-based serosurvey; HBT: Home-based testing; OR: Odds ratio; PICT: Provider initiated counselling and testing; RR: Relative risk; TB-Tuberculosis; USD: United States dollars; VCT: Voluntary counselling and testing; WHO: World Health Organization 


\begin{tabular}{|c|c|c|c|c|c|c|c|}
\hline Author & Country & Population & $\begin{array}{l}\text { Study } \\
\text { Design }\end{array}$ & Measurement & $\begin{array}{l}\text { Types of } \\
\text { exposures }\end{array}$ & Findings & Conclusions \\
\hline $\begin{array}{l}\text { Moreira et } \\
\text { al [68] }\end{array}$ & Cape Verde & $\begin{array}{l}191 \text { cases } \\
\text { and } 177 \\
\text { controls }\end{array}$ & $\begin{array}{l}\text { Case- } \\
\text { control }\end{array}$ & $\begin{array}{l}\text { Cases: HIV infected } \\
\text { individuals } \\
\text { presenting for care } \\
\text { with CD } 4 \text { count < } \\
350 \text { cells } / \mathrm{mm}^{3} \text {. } \\
\text { Controls: HIV } \\
\text { infected individuals } \\
\text { presenting for care } \\
\text { with CD } 4 \text { count } \geq \\
350 \text { cells } / \mathrm{mm}^{3} \text {. }\end{array}$ & $\begin{array}{l}\text { Age, gender, } \\
\text { level of } \\
\text { education, } \\
\text { employment, } \\
\text { marital status, } \\
\text { reason for HIV } \\
\text { testing, status } \\
\text { disclosure and } \\
\text { distance to a } \\
\text { health facility }\end{array}$ & - & $\begin{array}{l}\text { Older age ( } \geq 60 \text { years) } \\
\text { (AOR: } 3.19 ; 95 \% \mathrm{Cl} \text { : } \\
\text { 1.16-8.78) and } \\
\text { medical indication for } \\
\text { HIV testing (AOR: } 4.84 \text {; } \\
95 \% \mathrm{Cl} \text { : } 2.99-7.84 \text { ) } \\
\text { were associated with } \\
\text { late presentation for } \\
\text { care. }\end{array}$ \\
\hline $\begin{array}{l}\text { Gesesew et } \\
\text { al [11] }\end{array}$ & Ethiopia & $\begin{array}{l}4900 \text { HIV } \\
\text { infected } \\
\text { individuals }\end{array}$ & $\begin{array}{l}\text { Cohort } \\
\text { (2003- } \\
2015)\end{array}$ & $\begin{array}{l}\text { Late presentation } \\
\text { for care defined as } \\
\text { presentation with } \\
\text { CD } 4 \text { count }<200 \\
\text { cells } / \mathrm{mm}^{3} \text { if } \\
\text { enrolled between } \\
2003 \text { and } 2011 \text { and } \\
<350 \text { cells } / \mathrm{mm}^{3} \text { if } \\
\text { enrolled between } \\
2012 \text { and } 2015 \text { or } \\
\text { WHO clinical stage } \\
\text { III/IV in both } \\
\text { periods. }\end{array}$ & $\begin{array}{l}\text { Age, gender, } \\
\text { marital status, } \\
\text { educational } \\
\text { status, religion, } \\
\text { TB/HIV co- } \\
\text { infection, } \\
\text { baseline } \\
\text { functional } \\
\text { status and a } \\
\text { history of HIV } \\
\text { testing, }\end{array}$ & $\begin{array}{l}\text { Late } \\
\text { presentation } \\
\text { for care in } \\
66.7 \% \text { overall. }\end{array}$ & $\begin{array}{l}\text { Females (AOR:1.2; } 95 \% \\
\text { Cl: } 1.03-1.5 \text { ), TB/HIV } \\
\text { co-infected patients } \\
\text { (AOR:1.6; } 95 \% \text { Cl: } \\
\text { 1.09-2.1) and patients } \\
\text { without a previous } \\
\text { history of HIV testing } \\
\text { (AOR: } 1.2 ; 95 \% \text { Cl: } 1.1- \\
\text { 1.4) were more likely to } \\
\text { be presented late for } \\
\text { care whereas older } \\
\text { patients (25-50 years } \\
\text { and } 50+\text { years) } \\
\text { compared to younger } \\
\text { patients (15-24 years) } \\
\text { (AOR: } 0.4 ; 95 \% \text { Cl: } 0.3- \\
\text { 0.6) (AOR: } 0.4 ; 95 \% \text { Cl: } \\
\text { 0.2-0.6) were less } \\
\text { likely to be presented } \\
\text { late for care. }\end{array}$ \\
\hline $\begin{array}{l}\text { Kayabu et } \\
\text { al [58] }\end{array}$ & Tanzania & $\begin{array}{l}1096 \mathrm{HIV} \\
\text { infected } \\
\text { individuals }\end{array}$ & $\begin{array}{l}\text { Cross- } \\
\text { sectional }\end{array}$ & $\begin{array}{l}\text { Enrolment in care } \\
\text { within 3-months of } \\
\text { first HIV positive } \\
\text { test. }\end{array}$ & $\begin{array}{l}\text { Age, gender, } \\
\text { marital status, } \\
\text { baseline CD4 } \\
\text { count, WHO } \\
\text { stage and } \\
\text { referral site }\end{array}$ & $\begin{array}{l}91 \% \text { of } \\
\text { participants } \\
\text { enrolled in care } \\
\text { within 3- } \\
\text { months of HIV } \\
\text { diagnosis. }\end{array}$ & $\begin{array}{l}\text { Having a CD } 4 \text { count of } \\
50-199 \text { cells } / \mathrm{mm}^{3} \\
\text { (AOR: } 3.11 ; 95 \% \mathrm{Cl} \text { : } \\
\text { 1.14-8.50) was } \\
\text { associated with more } \\
\text { likelihood of linkage to } \\
\text { care. }\end{array}$ \\
\hline $\begin{array}{l}\text { Luma et al } \\
\text { [44] }\end{array}$ & Cameroon & $\begin{array}{l}1866 \mathrm{HIV} \\
\text { infected } \\
\text { individuals }\end{array}$ & $\begin{array}{l}\text { Cohort } \\
\text { (1996- } \\
2014)\end{array}$ & $\begin{array}{l}\text { Late presentation } \\
\text { for HIV care defined } \\
\text { as presentation } \\
\text { with a CD } 4 \text { count of } \\
<350 \text { cells } / \mathrm{mm}^{3} \text { or } \\
\text { WHO stages III/IV. }\end{array}$ & $\begin{array}{l}\text { Age, gender, } \\
\text { occupation, } \\
\text { employment, } \\
\text { religion, } \\
\text { marital status, } \\
\text { residence and } \\
\text { circumstance } \\
\text { of diagnosis }\end{array}$ & $\begin{array}{l}\text { Late } \\
\text { presentation } \\
\text { for care in } \\
89.7 \% \text { overall. }\end{array}$ & $\begin{array}{l}\text { Students compared to } \\
\text { employed people (AOR: } \\
0.50 ; 95 \% \mathrm{Cl} \text { : } 0.26- \\
0.98) \text { and those who } \\
\text { were diagnosed } \\
\text { through routine } \\
\text { screening compared to } \\
\text { clinical suspicion } \\
\text { (AOR: } 0.13 ; 95 \% \mathrm{Cl} \text { : } \\
0.10-0.19) \text { were less } \\
\text { likely to be late } \\
\text { presenters for care. }\end{array}$ \\
\hline $\begin{array}{l}\text { Cholera et } \\
\text { al [54] }\end{array}$ & South Africa & $\begin{array}{l}340 \text { HIV } \\
\text { infected } \\
\text { individuals }\end{array}$ & $\begin{array}{l}\text { Cross- } \\
\text { sectional }\end{array}$ & $\begin{array}{l}\text { Linkage to HIV care } \\
\text { defined as } \\
\text { obtaining a CD4 } \\
\text { count result within } \\
\text { 3-months of } \\
\text { diagnosis. }\end{array}$ & $\begin{array}{l}\text { Depression, } \\
\text { age, gender, } \\
\text { employment, } \\
\text { alcohol use, } \\
\text { perceived } \\
\text { health status } \\
\text { and baseline } \\
\text { CD4 count }\end{array}$ & $\begin{array}{l}\text { Linkage to } \\
\text { care in } 80 \% \text { of } \\
\text { depressed } \\
\text { patients and in } \\
73 \% \text { of non- } \\
\text { depressed } \\
\text { patients. }\end{array}$ & $\begin{array}{l}\text { Depression was not } \\
\text { associated with } \\
\text { linkage to care (RR: } \\
1.08 ; 95 \% \mathrm{Cl} \text { : } 0.96 \text {, } \\
1.23) \text {. }\end{array}$ \\
\hline $\begin{array}{l}\text { Kulkarni et } \\
\text { al [23] }\end{array}$ & Ethiopia & $\begin{array}{l}831 \mathrm{HIV} \\
\text { infected } \\
\text { individuals }\end{array}$ & $\begin{array}{l}\text { Cross- } \\
\text { sectional }\end{array}$ & $\begin{array}{l}\text { Time between } \\
\text { initial HIV-positive } \\
\text { diagnosis and } \\
\text { enrolment in care. }\end{array}$ & $\begin{array}{l}\text { Repeated HIV } \\
\text { testing }\end{array}$ & $\begin{array}{l}\text { Median time to } \\
\text { be linked to } \\
\text { care: } 12.3 \\
\text { months in } \\
\text { repeat testers; } \\
\text { 1-month in } \\
\text { single testers. }\end{array}$ & $\begin{array}{l}\text { Repeated HIV test was } \\
\text { associated with delay } \\
\text { in linkage to care; }>1 \\
\text { year delay time in } 15 \% \\
\text { of single testers } \\
\text { whereas in } 51 \% \text { of } \\
\text { repeat testers ( } P< \\
0.001) \text {. }\end{array}$ \\
\hline
\end{tabular}

AHR: Adjusted hazards ratio; AOR: Adjusted odds ratio; APRR: Adjusted prevalence risk ratio; ART: Antiretroviral therapy; ARV: Antiretroviral; ASHR: Adjusted sub-hazard ratio; CBSS: Community-based serosurvey; HBT: Home-based testing; OR: Odds ratio; PICT: Provider initiated counselling and testing; RR: Relative risk; TB-Tuberculosis; USD: United States dollars; VCT: Voluntary counselling and testing; WHO: World Health Organization 


\begin{tabular}{|c|c|c|c|c|c|c|c|}
\hline Author & Country & Population & $\begin{array}{l}\text { Study } \\
\text { Design }\end{array}$ & Measurement & $\begin{array}{l}\text { Types of } \\
\text { exposures }\end{array}$ & Findings & Conclusions \\
\hline $\begin{array}{l}\text { Maughan- } \\
\text { Brown et al } \\
{[56]}\end{array}$ & South Africa & $\begin{array}{l}86 \text { HIV } \\
\text { infected } \\
\text { individuals }\end{array}$ & $\begin{array}{l}\text { Cross- } \\
\text { sectional }\end{array}$ & $\begin{array}{l}\text { Linkage to care } \\
\text { defined as a visit to } \\
\text { a health facility } \\
\text { within 3-months of } \\
\text { diagnosis. }\end{array}$ & $\begin{array}{l}\text { Readiness for } \\
\text { treatment, } \\
\text { alcohol use, } \\
\text { perceived } \\
\text { stigma, belief } \\
\text { about ARV } \\
\text { side-effects, } \\
\text { denial of being } \\
\text { HIV-positive } \\
\text { and HIV status } \\
\text { disclosure }\end{array}$ & $\begin{array}{l}67 \% \text { of } \\
\text { participants } \\
\text { linked to care } \\
\text { within 3- } \\
\text { months. }\end{array}$ & $\begin{array}{l}\text { Disclosing HIV status } \\
\text { to someone other than } \\
\text { a sexual partner (AOR: } \\
2.99 ; 95 \% \text { Cl: } 1.13- \\
7.91 \text { ) and treatment } \\
\text { readiness (AOR: } 2.97 \text {; } \\
95 \% \text { Cl: } 1.05-8.34 \text { ) } \\
\text { were associated with } \\
\text { more likelihood of } \\
\text { linkage to care; people } \\
\text { who reported good } \\
\text { health (AOR: 0.35; } 95 \% \\
\text { Cl: } 0.13-0.99), \text { those } \\
\text { who drank alcohol at } \\
\text { least once weekly } \\
\text { (AOR: } 0.35 ; 95 \% \text { Cl: } \\
\text { 0.12-0.98) and those } \\
\text { who reported } \\
\text { experiencing } \\
\text { internalised stigma } \\
\text { (AOR: } 0.32 ; 95 \% \text { Cl: } \\
\text { 0.11-0.91) were less } \\
\text { likely to be linked to } \\
\text { care. }\end{array}$ \\
\hline $\begin{array}{l}\text { Teklu et al } \\
{[20]}\end{array}$ & Ethiopia & $\begin{array}{l}4159 \text { HIV } \\
\text { infected } \\
\text { individuals }\end{array}$ & $\begin{array}{l}\text { Cohort } \\
(2005- \\
2013)\end{array}$ & $\begin{array}{l}\text { Time from HIV } \\
\text { testing to } \\
\text { enrolment in care. }\end{array}$ & $\begin{array}{l}\text { Age, gender, } \\
\text { baseline WHO } \\
\text { stage and CD4 } \\
\text { count and HIV } \\
\text { status } \\
\text { disclosure }\end{array}$ & $\begin{array}{l}75 \% \text { of } \\
\text { participants } \\
\text { enrolled in care } \\
\text { within one } \\
\text { week. }\end{array}$ & $\begin{array}{l}\text { More care linkage time } \\
\text { was observed in people } \\
\text { with a higher CD4 } \\
\text { count (>349 } \\
\text { cells/mm } \mathrm{mm}^{3} \text { (AOR: } 1.77 \text {; } \\
95 \% \mathrm{Cl}: 1.37-2.27) \text {. }\end{array}$ \\
\hline $\begin{array}{l}\text { Maheu- } \\
\text { Giroux et al } \\
\text { [27] }\end{array}$ & South Africa & $\begin{array}{l}1733 \text { HIV } \\
\text { infected } \\
\text { individuals }\end{array}$ & $\begin{array}{l}\text { Cohort } \\
\text { study } \\
(2004- \\
2013)\end{array}$ & $\begin{array}{l}\text { Time from HIV } \\
\text { infection } \\
\text { (estimated as time } \\
\text { between previous } \\
\text { negative test and } \\
\text { first positive test) to } \\
\text { linkage to care. }\end{array}$ & $\begin{array}{l}\text { Age, gender, } \\
\text { education, } \\
\text { food security, } \\
\text { socioeconomic } \\
\text { status, } \\
\text { residence, } \\
\text { distance to a } \\
\text { clinic, } \\
\text { knowledge of } \\
\text { HIV status and } \\
\text { presence of a } \\
\text { household } \\
\text { member on } \\
\text { ART }\end{array}$ & $\begin{array}{l}4.9 \text { years for } \\
50 \% \text { of HIV } \\
\text { seroconverters. }\end{array}$ & $\begin{array}{l}\text { People of age } 40-49 \\
\text { years (AOR: } 1.54 ; \\
95 \% \mathrm{Cl} \text { : } 1.14-2.08 \text { ) and } \\
\text { those who were aware } \\
\text { of their HIV status from } \\
\text { previous testing (AOR: } \\
1.35 ; 95 \% \mathrm{Cl} \text { : } 1.09- \\
1.68 \text { ) were more likely } \\
\text { to be linked to care } \\
\text { whereas males were } \\
\text { less likely to be linked } \\
\text { to care compared to } \\
\text { women (AHR: } 0.49 ; \\
95 \% \mathrm{Cl}: 0.37-0.64) \text {. }\end{array}$ \\
\hline $\begin{array}{l}\text { Sanga et al } \\
{[45]}\end{array}$ & Tanzania & $\begin{array}{l}1012 \text { HIV } \\
\text { infected } \\
\text { individuals }\end{array}$ & $\begin{array}{l}\text { Cohort } \\
\text { (2014- } \\
2015)\end{array}$ & $\begin{array}{l}\text { Time to linkage to } \\
\text { care since HIV } \\
\text { diagnosis. }\end{array}$ & $\begin{array}{l}\text { Age, gender, } \\
\text { marital status, } \\
\text { time required } \\
\text { to reach a } \\
\text { clinic, testing } \\
\text { site, presence } \\
\text { of family } \\
\text { member taking } \\
\text { ARVs, reason } \\
\text { for diagnosis } \\
\text { and status } \\
\text { disclosure }\end{array}$ & $\begin{array}{l}78 \% \text { of } \\
\text { participants } \\
\text { linked to care } \\
\text { within 6- } \\
\text { months; } 84 \% \\
\text { for those } \\
\text { tested at } \\
\text { health facility; } \\
69 \% \text { for those } \\
\text { tested at } \\
\text { mobile sites. }\end{array}$ & $\begin{array}{l}\text { Having HIV diagnosis } \\
\text { at a health facility } \\
\text { (AHR: } 1.78 ; 95 \% \mathrm{Cl} \text { : } \\
\text { 1.52-2.07), disclosure } \\
\text { of HIV status (AOR: } \\
2.64 ; 95 \% \mathrm{Cl} \text { : } 2.05- \\
\text { 3.39) and intention to } \\
\text { get treatment as a } \\
\text { reason for diagnosis } \\
\text { (AOR: } 1.25 ; 95 \% \mathrm{Cl} \text { : } \\
\text { 1.06-1.45) were } \\
\text { associated with more } \\
\text { likelihood of linkage to } \\
\text { care. }\end{array}$ \\
\hline $\begin{array}{l}\text { Franse et al } \\
\text { [66] }\end{array}$ & Rwanda & $\begin{array}{l}403 \text { HIV } \\
\text { infected } \\
\text { individuals }\end{array}$ & $\begin{array}{l}\text { Cluster non- } \\
\text { randomised } \\
\text { trial }\end{array}$ & $\begin{array}{l}\text { Linkage to care } \\
\text { defined as } \\
\text { presentation to ART } \\
\text { clinic within } 90 \\
\text { days of HIV } \\
\text { diagnosis. }\end{array}$ & $\begin{array}{l}\text { Age, gender } \\
\text { and the } \\
\text { department } \\
\text { where } \\
\text { diagnosis was } \\
\text { made }\end{array}$ & $\begin{array}{l}\text { Linkage to } \\
\text { care in } 36.5 \% \\
\text { overall. }\end{array}$ & $\begin{array}{l}\text { None of the variables } \\
\text { were associated with } \\
\text { linkage to care. }\end{array}$ \\
\hline
\end{tabular}

AHR: Adjusted hazards ratio; AOR: Adjusted odds ratio; APRR: Adjusted prevalence risk ratio; ART: Antiretroviral therapy; ARV: Antiretroviral; ASHR: Adjusted sub-hazard ratio; CBSS: Community-based serosurvey; HBT: Home-based testing; OR: Odds ratio; PICT: Provider initiated counselling and testing; RR: Relative risk; TB-Tuberculosis; USD: United States dollars; VCT: Voluntary counselling and testing; WHO: World Health Organization 


\begin{tabular}{|c|c|c|c|c|c|c|c|}
\hline Author & Country & Population & $\begin{array}{l}\text { Study } \\
\text { Design }\end{array}$ & Measurement & $\begin{array}{l}\text { Types of } \\
\text { exposures }\end{array}$ & Findings & Conclusions \\
\hline $\begin{array}{l}\text { Reddy et al } \\
\text { [19] }\end{array}$ & Tanzania & $\begin{array}{l}240 \text { HIV } \\
\text { infected } \\
\text { individuals }\end{array}$ & $\begin{array}{l}\text { Cohort } \\
\text { (2008- } \\
2013)\end{array}$ & $\begin{array}{l}\text { Linkage to care } \\
\text { within 6-months of } \\
\text { diagnosis. }\end{array}$ & $\begin{array}{l}\text { Age, gender, } \\
\text { education, } \\
\text { marital status, } \\
\text { testing site, } \\
\text { depression, } \\
\text { stigma, social } \\
\text { support, } \\
\text { residence, } \\
\text { occupation, } \\
\text { wealth index } \\
\text { and reason for } \\
\text { testing }\end{array}$ & $\begin{array}{l}70.4 \% \text { of } \\
\text { participants } \\
\text { linked to care } \\
\text { within 6- } \\
\text { months; } 17.1 \% \\
\text { delayed more } \\
\text { than } 6 \text { months. }\end{array}$ & $\begin{array}{l}\text { Having HIV diagnosis } \\
\text { at community sites } \\
\text { (AOR: } 2.89 ; 95 \% \mathrm{Cl} \text { : } \\
\text { 1.79-4.66) was } \\
\text { associated with } \\
\text { delayed or no linkage } \\
\text { to care, but testing due } \\
\text { to illness had a } \\
\text { protective effect (AOR: } \\
0.58 ; 95 \% \mathrm{Cl} \text { : } 0.34- \\
0.96) \text {. }\end{array}$ \\
\hline $\begin{array}{l}\text { Takah et al } \\
\text { [57] }\end{array}$ & Cameroon & $\begin{array}{l}223 \text { HIV } \\
\text { infected } \\
\text { individuals }\end{array}$ & $\begin{array}{l}\text { Cross- } \\
\text { sectional }\end{array}$ & $\begin{array}{l}\text { Delayed linkage to } \\
\text { care defined as not } \\
\text { having a CD } 4 \text { count } \\
\text { measurement } \\
\text { within 3-months of } \\
\text { HIV diagnosis. }\end{array}$ & $\begin{array}{l}\text { Age, gender, } \\
\text { religion, } \\
\text { marital status, } \\
\text { educational } \\
\text { level, status } \\
\text { disclosure, } \\
\text { residence, time } \\
\text { taken to reach } \\
\text { ART site, } \\
\text { alcohol use } \\
\text { and presence } \\
\text { of chronic } \\
\text { diseases }\end{array}$ & $\begin{array}{l}\text { Delays in } \\
\text { linkage to care } \\
\text { in } 22.4 \% \\
\text { overall. }\end{array}$ & $\begin{array}{l}\text { Higher CD4 count (> } \\
\text { 500cells/mm } \mathrm{mm}^{3} \text { ) (AOR: } \\
3.60 ; 95 \% \mathrm{Cl}: 0.60- \\
\text { 10.40) and lower WHO } \\
\text { stages (I/II) (AOR: } 5.40 \text {; } \\
95 \% \mathrm{Cl}: 1.90-15.20) \\
\text { were associated with } \\
\text { delayed linage to care. }\end{array}$ \\
\hline $\begin{array}{l}\text { Kwobah et } \\
\text { al [15] }\end{array}$ & Kenya & $\begin{array}{l}10533 \text { HIV } \\
\text { infected } \\
\text { individuals }\end{array}$ & $\begin{array}{l}\text { Cross- } \\
\text { sectional }\end{array}$ & $\begin{array}{l}\text { Late engagement in } \\
\text { care defined as } \\
\text { having a baseline } \\
\text { CD } 4 \text { count } \leq 100 \\
\text { cells } / \mathrm{mm}^{3} \text {. }\end{array}$ & $\begin{array}{l}\text { Age, gender, } \\
\text { baseline CD4 } \\
\text { count, travel } \\
\text { time to clinic, } \\
\text { education, } \\
\text { disclosure } \\
\text { status, } \\
\text { economic } \\
\text { status, social } \\
\text { support, } \\
\text { alcohol use, } \\
\text { psychiatric } \\
\text { illness, TB } \\
\text { infection and } \\
\text { point of entry } \\
\text { into care }\end{array}$ & $\begin{array}{l}\text { Late } \\
\text { engagement in } \\
\text { care in } 23 \% \\
\text { overall. }\end{array}$ & $\begin{array}{l}\text { Male gender (AOR: } \\
\text { 1.54; 95\%Cl: } 1.35- \\
\text { 1.75), age > } 24 \text { years } \\
\text { (AOR: } 1.62 ; 95 \% \mathrm{Cl} \text { : } \\
\text { 1.02-2.56), more than } \\
\text { 1-hour travel time to a } \\
\text { clinic (AOR: } 1.18 ; \\
95 \% \mathrm{Cl} \text { : } 1.04-1.34 \text { ), } \\
\text { having TB infection } \\
\text { (AOR: } 2.77 ; 95 \% \mathrm{Cl} \text { : } \\
\text { 2.40-3.19) and } \\
\text { accessing care through } \\
\text { home-based } \\
\text { counselling and testing } \\
\text { services (AOR: } 2.98 ; \\
95 \% C l: 2.15-4.13) \\
\text { were associated with } \\
\text { late engagement in } \\
\text { care. }\end{array}$ \\
\hline $\begin{array}{l}\text { Nyika et al } \\
\text { [69] }\end{array}$ & Zimbabwe & $\begin{array}{l}134 \text { cases } \\
\text { and } 134 \\
\text { controls }\end{array}$ & $\begin{array}{l}\text { Case- } \\
\text { control }\end{array}$ & $\begin{array}{l}\text { Cases: HIV infected } \\
\text { individuals with a } \\
\text { baseline CD } 4 \text { of < } \\
200 / \mathrm{mm}^{3} \text { or WHO } \\
\text { clinical stage III/IV. } \\
\text { Controls: HIV } \\
\text { infected individuals } \\
\text { with a baseline CD4 } \\
\text { of } \geq 200 / \mathrm{mm}^{3} \text { or } \\
\text { WHO clinical stage } \\
\text { I/II. }\end{array}$ & $\begin{array}{l}\text { Age, gender, } \\
\text { marital status, } \\
\text { residence, } \\
\text { monthly } \\
\text { income, } \\
\text { education, } \\
\text { religion, reason } \\
\text { for HIV testing, } \\
\text { stigma and } \\
\text { receipt of HIV } \\
\text { information }\end{array}$ & - & $\begin{array}{l}\text { Male gender (AOR:7.68; } \\
95 \% \text { Cl: } 4.08-14.75) \text {, } \\
\text { having HIV diagnosis } \\
\text { due to illness } \\
\text { (AOR:2.99; } \\
\text { 95\%Cl:1.54-5.79) and } \\
\text { stigma } \\
\text { (AOR:2.99:95\%Cl:1.54- } \\
5.79 \text { ) were associated } \\
\text { with late presentation } \\
\text { for care; receiving } \\
\text { information on HIV } \\
\text { (AOR:0.37; } 95 \% \mathrm{Cl}: \\
\text { 0.18-0.78) and } \\
\text { earning a monthly } \\
\text { income of > USD250 } \\
\text { (AOR:0.32; } 95 \% \mathrm{Cl}: 0.76 \\
\text { - } 0.67 \text { ) had a } \\
\text { protective effect. }\end{array}$ \\
\hline
\end{tabular}

AHR: Adjusted hazards ratio; AOR: Adjusted odds ratio; APRR: Adjusted prevalence risk ratio; ART: Antiretroviral therapy; ARV: Antiretroviral; ASHR: Adjusted sub-hazard ratio; CBSS: Community-based serosurvey; HBT: Home-based testing; OR: Odds ratio; PICT: Provider initiated counselling and testing; RR: Relative risk; TB-Tuberculosis; USD: United States dollars; VCT: Voluntary counselling and testing; WHO: World Health Organization 


\begin{tabular}{|c|c|c|c|c|c|c|c|}
\hline Author & Country & Population & $\begin{array}{l}\text { Study } \\
\text { Design }\end{array}$ & Measurement & $\begin{array}{l}\text { Types of } \\
\text { exposures }\end{array}$ & Findings & Conclusions \\
\hline $\begin{array}{l}\text { Billioux et } \\
\text { al [46] }\end{array}$ & Uganda & $\begin{array}{l}3666 \text { HIV } \\
\text { infected } \\
\text { individuals }\end{array}$ & $\begin{array}{l}\text { Cohort } \\
(2013- \\
2015)\end{array}$ & $\begin{array}{l}\text { Linkage to care } \\
\text { defined as } \\
\text { completing } \\
\text { at least one clinic } \\
\text { visit and/or self- } \\
\text { reported use of } \\
\text { Cotrimoxazole/ART. }\end{array}$ & $\begin{array}{l}\text { Age gender, } \\
\text { education, } \\
\text { marital status, } \\
\text { religion, } \\
\text { occupation, } \\
\text { income and } \\
\text { community } \\
\text { type }\end{array}$ & $\begin{array}{l}\text { Linkage to } \\
\text { care in } 74 \% \\
\text { overall. }\end{array}$ & $\begin{array}{l}\text { Males (APRR: } 0.84 ; \\
95 \% \mathrm{Cl} \text { : } 0.77-0.91) \text {, } \\
\text { people of younger age } \\
\text { (15-24 years) (APRR: } \\
0.72 ; 95 \% \mathrm{Cl} \text { : } 0.63- \\
0.82 \text { ) and those who } \\
\text { have never married } \\
\text { (APRR: } 0.84 ; 95 \% \mathrm{Cl} \text { : } \\
0.71-0.99) \text { were less } \\
\text { likely to be enrolled in } \\
\text { care. }\end{array}$ \\
\hline $\begin{array}{l}\text { Boeke et al } \\
\text { [47] }\end{array}$ & Uganda & $\begin{array}{l}928 \text { HIV } \\
\text { infected } \\
\text { individuals }\end{array}$ & $\begin{array}{l}\text { Cohort } \\
(2015- \\
2016)\end{array}$ & $\begin{array}{l}\text { Linkage to care } \\
\text { defined as } \\
\text { registering for pre- } \\
\text { ART or ART care } \\
\text { within 1-month of } \\
\text { HIV diagnosis. }\end{array}$ & $\begin{array}{l}\text { Age, gender, } \\
\text { facility and } \\
\text { location }\end{array}$ & $\begin{array}{l}\text { Linkage to } \\
\text { care in } 53 \% \\
\text { overall. }\end{array}$ & $\begin{array}{l}\text { Linkage to care was } \\
\text { lower in rural health } \\
\text { facilities compared to } \\
\text { urban health facilities } \\
\text { (AOR: } 0.64 ; 95 \% \mathrm{Cl} \text { : } \\
0.43-0.95 \text { ) and in } \\
\text { adolescents (age } 10- \\
18 \text { years) compared to } \\
\text { adults (age } 19-48 \\
\text { years) (AOR: } 0.58 ; \\
95 \% \mathrm{Cl}: 0.35-0.96) \text {. }\end{array}$ \\
\hline $\begin{array}{l}\text { Fomundam } \\
\text { et al [7] }\end{array}$ & South Africa & $\begin{array}{l}8138 \text { HIV } \\
\text { infected } \\
\text { individuals }\end{array}$ & $\begin{array}{l}\text { Cross- } \\
\text { sectional }\end{array}$ & $\begin{array}{l}\text { Late presentation } \\
\text { for HIV care refers } \\
\text { to diagnosis at CD } 4 \\
\text { count } \leq 500 \\
\text { cells/mm }{ }^{3} \text { and/or } \\
\text { at any of the WHO } \\
\text { stages. }\end{array}$ & $\begin{array}{l}\text { Age, gender } \\
\text { and facility } \\
\text { location }\end{array}$ & $\begin{array}{l}\text { Late } \\
\text { presentation } \\
\text { for car in } 78 \% \\
\text { overall. }\end{array}$ & $\begin{array}{l}\text { Higher likelihood of } \\
\text { late presentation for } \\
\text { care in males } \\
\text { (AOR:2.73; } \\
95 \% \text { Cl: } 1.50-4.94) \text {, } \\
\text { people of older age (> } \\
40 \text { years) (AOR: } 2.72 ; \\
95 \% \mathrm{Cl} \text { : } 2.02-3.66 \text { ) and } \\
\text { in those accessing care } \\
\text { from urban health } \\
\text { facilities (AOR:1.59; } \\
95 \% \mathrm{Cl}: 1.34-1.90)\end{array}$ \\
\hline $\begin{array}{l}\text { Honge et al } \\
{[48]}\end{array}$ & $\begin{array}{l}\text { Guinea- } \\
\text { Bissau }\end{array}$ & $\begin{array}{l}3720 \text { HIV } \\
\text { infected } \\
\text { individuals }\end{array}$ & $\begin{array}{l}\text { Cohort } \\
(2005- \\
2013)\end{array}$ & $\begin{array}{l}\text { Late presentation } \\
\text { for care defined as } \\
\text { presentation with a } \\
\text { CD } 4 \text { count below } \\
200 \text { cells } / \mathrm{mm}^{3} \text {. }\end{array}$ & $\begin{array}{l}\text { Age, gender, } \\
\text { marital status } \\
\text { and education }\end{array}$ & $\begin{array}{l}\text { Late } \\
\text { presentation } \\
\text { for care in } 49 \% \\
\text { overall. }\end{array}$ & $\begin{array}{l}\text { Male gender (AOR: } \\
\text { 1.49; } 95 \% \mathrm{Cl} \text { : 1.24- } \\
\text { 1.80), having no } \\
\text { partner (AOR: } 1.30 \text {; } \\
\text { 95\%Cl: } 1.05-1.61 \text { ) and } \\
\text { age > 30 years (AOR: } \\
\text { 1.66; } 95 \% \mathrm{Cl} \text { : } 1.36- \\
\text { 2.02) were risk factors } \\
\text { for late presentation } \\
\text { for care. }\end{array}$ \\
\hline $\begin{array}{l}\text { Lopez- } \\
\text { Varela et al } \\
\text { [49] }\end{array}$ & Mozambique & $\begin{array}{l}1112 \text { HIV } \\
\text { infected } \\
\text { individuals }\end{array}$ & $\begin{array}{l}\text { Cohort } \\
(2014- \\
2015)\end{array}$ & $\begin{array}{l}\text { Linkage to care } \\
\text { defined as having a } \\
\text { first CD4 count } \\
\text { available within 3- } \\
\text { months of } \\
\text { diagnosis. }\end{array}$ & $\begin{array}{l}\text { Age, gender, } \\
\text { clinical stage } \\
\text { and testing } \\
\text { modality }\end{array}$ & $\begin{array}{l}\text { Linkage to } \\
\text { care in } 74 \% \\
\text { overall. }\end{array}$ & $\begin{array}{l}\text { Older age (>35 years) } \\
\text { (ASHR: } 2.17 ; \\
\text { 95\%Cl: } 1.56-3.01) \text {, } \\
\text { having a previous } \\
\text { negative HIV test } \\
\text { (ASHR: } 1.43 ; \\
\text { 95\%Cl:1.16-1.76) and } \\
\text { advanced WHO stage } \\
\text { (stage III/IV) } \\
\text { (ASHR:1.46; } \\
\text { 95\%Cl:1.14-1.87) were } \\
\text { positively associated } \\
\text { with linkage to care } \\
\text { whereas HBT (ASHR: } \\
\text { 0.62; } 95 \% \text { Cl: 0.47- } \\
\text { 0.83) and PICT(ASHR: } \\
\text { 0.76; } 95 \% \text { Cl: } 0.61- \\
\text { 0.94) were negatively } \\
\text { associated with } \\
\text { linkage to care } \\
\text { compared to VCT. }\end{array}$ \\
\hline
\end{tabular}

AHR: Adjusted hazards ratio; AOR: Adjusted odds ratio; APRR: Adjusted prevalence risk ratio; ART: Antiretroviral therapy; ARV: Antiretroviral; ASHR: Adjusted sub-hazard ratio; CBSS: Community-based serosurvey; HBT: Home-based testing; OR: Odds ratio; PICT: Provider initiated counselling and testing; RR: Relative risk; TB-Tuberculosis; USD: United States dollars; VCT: Voluntary counselling and testing; WHO: World Health Organization 


\begin{tabular}{|c|c|c|c|c|c|c|c|}
\hline Author & Country & Population & $\begin{array}{l}\text { Study } \\
\text { Design }\end{array}$ & Measurement & $\begin{array}{l}\text { Types of } \\
\text { exposures }\end{array}$ & Findings & Conclusions \\
\hline $\begin{array}{l}\text { Rane et al } \\
{[50]}\end{array}$ & South Africa & $\begin{array}{l}1271 \text { HIV } \\
\text { infected } \\
\text { individuals }\end{array}$ & $\begin{array}{l}\text { Cohort } \\
(2013- \\
2016)\end{array}$ & $\begin{array}{l}\text { Delayed } \\
\text { presentation for } \\
\text { care defined as a } \\
\text { gap of }>90 \text { days } \\
\text { between the first } \\
\text { HIV-positive test } \\
\text { and study } \\
\text { enrolment. }\end{array}$ & $\begin{array}{l}\text { Age, gender, } \\
\text { stigma, } \\
\text { depression } \\
\text { and anxiety }\end{array}$ & - & $\begin{array}{l}\text { Severe depression } \\
\text { (AOR: } 3.6 ; 95 \% \mathrm{Cl}: 1.2- \\
\text { 10.2) and anxiety } \\
\text { (AOR: } 2.3 ; 95 \% \mathrm{Cl} \text { : } 1.3- \\
\text { 4.2) were associated } \\
\text { with delayed } \\
\text { presentation for care. }\end{array}$ \\
\hline $\begin{array}{l}\text { Rentsch et } \\
\text { al [12] }\end{array}$ & Tanzania & $\begin{array}{l}411 \mathrm{HIV} \\
\text { infected } \\
\text { individuals }\end{array}$ & $\begin{array}{l}\text { Cohort } \\
\text { (2014- } \\
2017)\end{array}$ & $\begin{array}{l}\text { Linkage to care } \\
\text { defined as first visit } \\
\text { to the treatment } \\
\text { centre within } 90 \\
\text { days of diagnosis. }\end{array}$ & $\begin{array}{l}\text { Age, gender } \\
\text { and distance } \\
\text { to a health } \\
\text { facility }\end{array}$ & $\begin{array}{l}\text { Linkage to } \\
\text { care in } 23.8 \% \\
\text { overall; } 52.7 \% \\
\text { in those who } \\
\text { were } \\
\text { diagnosed } \\
\text { using VCT; } \\
17.7 \% \text { in PICT } \\
\text { cases; } 10.2 \% \\
\text { in CBSS cases. }\end{array}$ & $\begin{array}{l}\text { Higher hazards of } \\
\text { linkage to care was } \\
\text { observed in facility- } \\
\text { based VCT compared } \\
\text { to community-based } \\
\text { sero-survey (AHR: } \\
6.95 ; 95 \% \mathrm{Cl} \text { : } 4.39- \\
11.00 \text { ) and in } \\
\text { individuals whose } \\
\text { house is < } 1 \mathrm{~km} \text { away } \\
\text { from the treatment } \\
\text { centre compared to } \\
\text { that } \geq 5 \mathrm{~km} \text { (AHR: } 4.67 \text {; } \\
95 \% \mathrm{Cl}: 1.16-18.76 \text { ). }\end{array}$ \\
\hline $\begin{array}{l}\text { Lifson et al } \\
\text { [59] }\end{array}$ & Ethiopia & $\begin{array}{l}1799 \text { HIV } \\
\text { infected } \\
\text { individuals }\end{array}$ & $\begin{array}{l}\text { Cross- } \\
\text { sectional }\end{array}$ & $\begin{array}{l}\text { Advanced HIV } \\
\text { disease (defined as } \\
\text { CD4 count < } 200 \\
\text { cells/mm } \text { or WHO }^{3} \text { or } \\
\text { stage III/IV) at } \\
\text { enrolment to care. }\end{array}$ & $\begin{array}{l}\text { Age, gender, } \\
\text { marital status } \\
\text { and } \\
\text { occupation }\end{array}$ & $\begin{array}{l}\text { Advanced HIV } \\
\text { disease in } 60 \% \\
\text { overall; } 66 \% \text { in } \\
\text { males and } \\
56 \% \text { in } \\
\text { females. }\end{array}$ & $\begin{array}{l}\text { Male gender }(\mathrm{P}< \\
0.001) \text { and } \\
\text { unemployment }(\mathrm{P}< \\
0.001) \text { were } \\
\text { significantly } \\
\text { associated with an } \\
\text { advanced HIV disease; } \\
\text { individuals of age } \leq 25 \\
\text { years were less likely to } \\
\text { have an advanced HIV } \\
\text { disease }(\mathrm{P}=0.002) \text {. }\end{array}$ \\
\hline $\begin{array}{l}\text { Hoffman et } \\
\text { al [70] }\end{array}$ & South Africa & $\begin{array}{l}459 \text { HIV } \\
\text { infected } \\
\text { individuals }\end{array}$ & $\begin{array}{l}\text { Cohort } \\
(2010- \\
2013)\end{array}$ & $\begin{array}{l}\text { Linkage to care } \\
\text { defined as return to } \\
\text { a clinic for CD4 } \\
\text { count results within } \\
\text { 3-months of } \\
\text { diagnosis. }\end{array}$ & $\begin{array}{l}\text { Age, gender, } \\
\text { marital status, } \\
\text { education, } \\
\text { employment, } \\
\text { stigma, } \\
\text { disclosure, } \\
\text { depression, } \\
\text { coping } \\
\text { strategy, travel } \\
\text { time to a clinic, } \\
\text { baseline WHO } \\
\text { stage and } \\
\text { belief in ART } \\
\text { safety and } \\
\text { efficacy }\end{array}$ & $\begin{array}{l}\text { Linkage to } \\
\text { care in } 54.1 \% \\
\text { overall. }\end{array}$ & $\begin{array}{l}\text { Age < } 30 \text { years (AOR: } \\
0.52 ; 95 \% \text { Cl: } 0.33- \\
0.82 \text { ), holding positive- } \\
\text { outcome belief in care } \\
\text { (AOR: } 0.50 ; 95 \% \text { Cl: } \\
0.33-0.75) \text {, belief in } \\
\text { ART efficacy (AOR: } \\
0.29 ; 95 \% \text { Cl: } 0.14- \\
0.61) \text {, positive } \\
\text { reframing as a coping } \\
\text { strategy (AOR: } 0.74 ; \\
95 \% C l: 0.55-0.99 \text { ) and } \\
\text { disclosure of HIV } \\
\text { status (AOR: } 0.40 ; \\
95 \% C l: 0.21-0.75 \text { ) } \\
\text { were associated with } \\
\text { lower odds of non- } \\
\text { linkage to care. }\end{array}$ \\
\hline $\begin{array}{l}\text { Maughan- } \\
\text { Brown et al } \\
\text { [60] }\end{array}$ & South Africa & $\begin{array}{l}183 \text { HIV } \\
\text { infected } \\
\text { individuals }\end{array}$ & $\begin{array}{l}\text { Cross- } \\
\text { sectional }\end{array}$ & $\begin{array}{l}\text { Linkage to care } \\
\text { defined as first visit } \\
\text { to an HIV clinic } \\
\text { within } 12 \text {-weeks of } \\
\text { HIV testing. }\end{array}$ & $\begin{array}{l}\text { Age, gender, } \\
\text { education, } \\
\text { monthly } \\
\text { income, } \\
\text { marital status, } \\
\text { previous HIV } \\
\text { diagnosis, } \\
\text { baseline CD4 } \\
\text { count, stigma, } \\
\text { HIV status } \\
\text { disclosure, } \\
\text { depression } \\
\text { and emotional } \\
\text { support }\end{array}$ & $\begin{array}{l}\text { Linkage to } \\
\text { care in } 55 \% \\
\text { overall. }\end{array}$ & $\begin{array}{l}\text { Thinking that test } \\
\text { results were wrong was } \\
\text { associated with lower } \\
\text { odds of linkage to care } \\
\text { (AOR: } 0.46 ; 95 \% \mathrm{Cl} \text { : } \\
0.23-0.93 \text { ) whereas } \\
\text { disclosure of HIV } \\
\text { status to someone } \\
\text { increased the } \\
\text { likelihood of care } \\
\text { linkage (AOR: } 2.31 \text { : } \\
95 \% \text { Cl: } 1.07-4.97) \text {. }\end{array}$ \\
\hline
\end{tabular}

AHR: Adjusted hazards ratio; AOR: Adjusted odds ratio; APRR: Adjusted prevalence risk ratio; ART: Antiretroviral therapy; ARV: Antiretroviral; ASHR: Adjusted sub-hazard ratio; CBSS: Community-based serosurvey; HBT: Home-based testing; OR: Odds ratio; PICT: Provider initiated counselling and testing; RR: Relative risk; TB-Tuberculosis; USD: United States dollars; VCT: Voluntary counselling and testing; WHO: World Health Organization 


\begin{tabular}{|c|c|c|c|c|c|c|c|}
\hline Author & Country & Population & $\begin{array}{l}\text { Study } \\
\text { Design }\end{array}$ & Measurement & $\begin{array}{l}\text { Types of } \\
\text { exposures }\end{array}$ & Findings & Conclusions \\
\hline $\begin{array}{l}\text { Haskew et } \\
\text { al [61] }\end{array}$ & Kenya & $\begin{array}{l}1752 \text { HIV } \\
\text { infected } \\
\text { individuals }\end{array}$ & $\begin{array}{l}\text { Cross- } \\
\text { sectional }\end{array}$ & $\begin{array}{l}\text { Late linkage to care } \\
\text { defined as having } \\
\text { WHO stage III/IV or } \\
\text { CD } 4 \text { count } \leq 350 \\
\text { cells/mm } 3 \mathrm{~mm}^{3} \text { at first } \\
\text { clinic visit. }\end{array}$ & $\begin{array}{l}\text { Age, gender, } \\
\text { marital status } \\
\text { and HIV } \\
\text { testing source }\end{array}$ & $\begin{array}{l}\text { Late linkage to } \\
\text { care in } 27.3 \% \\
\text { overall based } \\
\text { on WHO stage } \\
\text { and } 65.5 \% \\
\text { based on CD4 } \\
\text { count. }\end{array}$ & $\begin{array}{l}\text { Having HIV test via } \\
\text { VCT compared to } \\
\text { community-based } \\
\text { testing (AOR: } 2.39 ; \\
95 \% \text { Cl: } 1.24-4.60) \\
\text { being male (AOR: } 1.38 \text {; } \\
1.04-1.83 \text { ), being } \\
\text { divorced/widowed } \\
\text { (AOR: } 1.55 ; 95 \% \text { Cl: } \\
\text { 1.15-2.08) and being } \\
\text { in the age group of < } \\
50 \text { years (AOR: } 1.72 ; \\
95 \% C l: 1.09-2.74) \\
\text { were significantly } \\
\text { associated with late } \\
\text { linkage to care. }\end{array}$ \\
\hline
\end{tabular}

AHR: Adjusted hazards ratio; AOR: Adjusted odds ratio; APRR: Adjusted prevalence risk ratio; ART: Antiretroviral therapy; ARV: Antiretroviral; ASHR: Adjusted sub-hazard ratio; CBSS: Community-based serosurvey; HBT: Home-based testing; OR: Odds ratio; PICT: Provider initiated counselling and testing; RR: Relative risk; TB-Tuberculosis; USD: United States dollars; VCT: Voluntary counselling and testing; WHO: World Health Organization

From studies investigating the prevalence of late presentation for care, a South African study [7] reported a prevalence of 78\% (late presentation: CD4 count $\leq 500$ cells $/ \mathrm{mm}^{3}$ ) whereas a Kenyan study [61] identified $66 \%$ (late presentation: CD4 count $\leq 350$ cells/mm ${ }^{3}$ ). Two Ethiopian studies [11, 59] reported prevalences of $67 \%$ and $60 \%$, when considering baseline CD4 counts of $<200$ cells $/ \mathrm{mm}^{3}$ as late presentation for care. Another study in Kenya [15] identified a prevalence of $23 \%$, defining late presentation as engagement in care at CD 4 count $\leq 100$ cells $/ \mathrm{mm}^{3}$.

Structural, psychosocial, behavioural and sociodemographic factors were reported to be associated with late linkage to care. Eight studies identified healthcare delivery factors $[7,12,15,19,45,47,49,61]$. More than an hour travel time to reach a clinic [12, 15], accessing care at a rural healthcare facility compared to an urban health facility, and having diagnosis through community-based approaches compared to health facility-based approaches were identified as risk factors for late linkage to care [12, 15, 19, 45, 47, 49]. In contrast, Fomundam et al [7] in South Africa identified a higher likelihood of late presentation for care in PLWH who were accessing care from urban health care facilities, as did Haskew et al [61] in those who were diagnosed through health facility-based approaches in Kenya.

Fifteen studies reported associations between behavioural or psychosocial factors and late linkage to care $[11,17,19,23,27,44,45,49,50,56,60$, 67-70]. Testing because of illness [19, 44, 45, 68, 69], having a previous history of HIV diagnosis [11, 27, 49], readiness for treatment [56], holding a positive-outcome belief in care and using positive reframing as a coping strategy [70] increased the likelihood of linkage to care. Non-disclosure of HIV status [17, 45, 56, 60,67, 70], a desire for repeated testing [23,60], an experience or fear of stigma [56, 67, 69], having low household social support [67] and having severe depression and anxiety [50] increased delays in care linkage. Six studies reported perceptions related to clinical conditions as barriers to linkage to care $[11,15,20,49,57,58]$. Four of these reported lower odds of linkage to care in PLWH having a higher CD4 count $\left(\geq 500 \mathrm{cell} / \mathrm{mm}^{3}\right.$ ) and/or a lower WHO clinical stage (I/II) $[20,49,57,58]$. The remaining two linked the presence of TB co-infection with late linkage to care $[11,15]$.

Sociodemographic characteristics such as: age, gender, marital status, employment and wealth index influenced linkage to care. Younger age (below 30 years) $[11,15,17,27,46,47,49,67,70]$, male gender $[7,15,17,27,46,48,59,61,69]$, lacking a partner $[11,46,48,61]$, being employed [17, 44] and having a low wealth index $[67,69]$ were most associated with late linkage to care.

\section{ART initiation}

Results of studies that investigated ART initiation are presented in Table 2. Two studies in South Africa [53, 64] investigated same day ART initiation and reported prevalence of $20 \%$ and $40 \%$ respectively. Among studies that investigated the rate of ART initiation at various time intervals after diagnosis, one study in Rwanda [66] reported a rate of 52\% within three months, and two studies in South Africa reported 72\% [53] and 62\% [52] within one and six months of diagnosis respectively. Among studies that reported the rate of ART initiation within three, six and twelve months of care engagement, the rate ranged from $62-82 \%$ within three months $[56,65], 57-89 \%$ within six months $[39,65]$ and $59-92 \%$ within twelve months $[12,39]$. One study in South Africa reported ART initiation in $50 \%$ of PLWH within one month of care engagement [65]. 
Table 2

Characteristics of studies investigating initiation of antiretroviral therapy

\begin{tabular}{|c|c|c|c|c|c|c|c|}
\hline Author & Country & Population & $\begin{array}{l}\text { Study } \\
\text { Design }\end{array}$ & Measurement & $\begin{array}{l}\text { Types of } \\
\text { exposures }\end{array}$ & Findings & Conclusions \\
\hline $\begin{array}{l}\text { Bor et al } \\
\text { [39] }\end{array}$ & South Africa & $\begin{array}{l}4630 \text { ART } \\
\text { eligible } \\
\text { people } \\
\text { (CD4 } \\
\text { count } \leq \\
350 \\
\text { cells } / \mathrm{mm}^{3} \text { ) }\end{array}$ & $\begin{array}{l}\text { Cohort } \\
\text { (2012- } \\
2013)\end{array}$ & $\begin{array}{l}\text { Time from } \\
\text { the date of } \\
\text { first record of } \\
\text { CD4 count to } \\
\text { date of ART } \\
\text { initiation. }\end{array}$ & $\begin{array}{l}\text { Age, gender, } \\
\text { distance to a } \\
\text { clinic, } \\
\text { residence, } \\
\text { presence of } \\
\text { previously } \\
\text { HIV care } \\
\text { linked } \\
\text { household } \\
\text { member, } \\
\text { employment } \\
\text { status, wealth } \\
\text { index and } \\
\text { CD4 count }\end{array}$ & $\begin{array}{l}\text { ART initiation } \\
\text { in } 57 \% \\
\text { overall within } \\
6 \text {-months; } \\
67 \% \text { in } \\
\text { patients with } \\
\text { CD4 } 4 \\
50 \text { cells } / \mathrm{mm}^{3} \text {; } \\
48 \% \text { in } \\
\text { patients with } \\
\text { CD } 4 \text { count } \\
301-350 \\
\text { cells } / \mathrm{mm}^{3} \text {. }\end{array}$ & $\begin{array}{l}\text { The hazards of ART initiation } \\
\text { fell by } 17 \% \text { for every } 100 \text { cell } \\
\text { increase in baseline CD } 4 \text { count; } \\
\text { higher rate of ART initiation } \\
\text { among older patients (age }>55 \\
\text { years) compared to younger } \\
\text { patients (age } 18-24 \text { years) (HR: } \\
1.65 ; 95 \% \text { Cl: } 1.27-2.15) \text {. }\end{array}$ \\
\hline $\begin{array}{l}\text { Boyer et al } \\
\text { [65] }\end{array}$ & South Africa & $\begin{array}{l}514 \text { HIV } \\
\text { infected } \\
\text { individuals }\end{array}$ & $\begin{array}{l}\text { Cluster } \\
\text { randomized } \\
\text { trial }(2012- \\
2015)\end{array}$ & $\begin{array}{l}\text { ART initiation } \\
\text { defined as } \\
\text { the first time } \\
\text { antiretroviral } \\
\text { therapy } \\
\text { dispensed } \\
\text { since } \\
\text { baseline } \\
\text { clinic visit } \\
\text { (either } \\
\text { offered } \\
\text { immediate } \\
\text { ART or at } \\
\text { CD4 count } \leq \\
350 \\
\text { cells } / \mathrm{mm}^{3} \text { ). }\end{array}$ & $\begin{array}{l}\text { Age, gender, } \\
\text { education, } \\
\text { household } \\
\text { wealth, } \\
\text { perception of } \\
\text { stigma, } \\
\text { distance } \\
\text { between } \\
\text { homesteads } \\
\text { and clinic, } \\
\text { having a } \\
\text { regular } \\
\text { partner, HIV- } \\
\text { status } \\
\text { disclosure, } \\
\text { social } \\
\text { support, } \\
\text { psychological } \\
\text { distress, time } \\
\text { between } \\
\text { referral and } \\
\text { baseline } \\
\text { clinic visit } \\
\text { and baseline } \\
\text { cD4 count }\end{array}$ & $\begin{array}{l}\text { Median } \\
\text { duration for } \\
\text { ART } \\
\text { initiation: } \\
1.08 \text { (range: } \\
0.69-2.09 \text { ) } \\
\text { months; } \\
\text { overall rate } \\
\text { of ART } \\
\text { initiation: } \\
49.5 \% \text { at first } \\
\text { month; } \\
82.2 \% \text { at } \\
\text { third month; } \\
\text { and } 88.7 \% \text { at } \\
\text { sixth month. }\end{array}$ & $\begin{array}{l}\text { Patients with CD } 4 \text { count of }> \\
350 \text { cells/mm } 3 \text { compared to } \\
\text { those with CD } 4 \text { count } \leq 100 \\
\text { cells/mm } / \mathrm{mm}^{3} \text { (HR: } 0.3 ; 95 \% \mathrm{Cl}: 0.2- \\
0.4 \text { ) and those without a regular } \\
\text { partner (HR: } 0.5 ; 95 \% \mathrm{Cl}: 0.4- \\
0.8) \text { were less likely to initiate } \\
\text { ART whereas patients of } \geq 50 \\
\text { years of age initiate ART more } \\
\text { compared to those aged } 16-29 \\
\text { years (HR: } 1.5 ; 95 \% \text { Cl: } 1.0-2.3) \text {. }\end{array}$ \\
\hline $\begin{array}{l}\text { Brown et al } \\
\text { [13] }\end{array}$ & Malawi & $\begin{array}{l}617 \text { HIV } \\
\text { infected } \\
\text { individuals } \\
\text { enrolled in } \\
\text { care }\end{array}$ & $\begin{array}{l}\text { Cohort } \\
\text { (2008- } \\
2015)\end{array}$ & $\begin{array}{l}\text { ART initiation } \\
\text { after } \\
\text { enrolment in } \\
\text { care }\end{array}$ & $\begin{array}{l}\text { Age, gender, } \\
\text { CD } 4 \text { count at } \\
\text { enrolment } \\
\text { and route of } \\
\text { HIV testing }\end{array}$ & $\begin{array}{l}\text { ART initiation } \\
\text { in } 84 \% \\
\text { overall; } \\
65.7 \% \text { within } \\
\text { 3-months; } \\
\text { median time } \\
\text { of ART } \\
\text { initiation } \\
\text { from HIV } \\
\text { testing: } 59 \\
\text { days; } 189 \\
\text { days in those } \\
\text { tested } \\
\text { through HIV } \\
\text { serosurvey; } \\
\text { 16 days in } \\
\text { those tested } \\
\text { at ART clinic. }\end{array}$ & $\begin{array}{l}\text { Lower ART initiation rate was } \\
\text { observed in those who had a } \\
\text { CD4 count of }>500 \text { cells } / \mathrm{mm}^{3} \\
\text { compared to those who had } \leq \\
350 \text { cells/mm } \mathrm{mm}^{3} \text { (HR: } 0.12 ; 95 \% \mathrm{Cl} \text { : } \\
0.09-0.17 \text { ) and in those who } \\
\text { tested through HIV serosurvey } \\
\text { compared to those who were } \\
\text { tested at ART clinic (HR: } 0.75 \text {; } \\
95 \% \mathrm{Cl}: 0.62-0.91 \text { ). }\end{array}$ \\
\hline $\begin{array}{l}\text { *Cholera et } \\
\text { al [54] }\end{array}$ & South Africa & $\begin{array}{l}\text { 176 ART } \\
\text { eligible } \\
\text { people } \\
\text { (CD4 count } \\
\leq 350 \\
\text { cells } / \mathrm{mm}^{3} \text { ) }\end{array}$ & $\begin{array}{l}\text { Cross- } \\
\text { sectional }\end{array}$ & $\begin{array}{l}\text { Initiation of } \\
\text { ART within 3- } \\
\text { months of } \\
\text { staging visit } \\
\text { or within 6- } \\
\text { months of } \\
\text { HIV testing }\end{array}$ & $\begin{array}{l}\text { Age, gender, } \\
\text { employment, } \\
\text { depression, } \\
\text { alcohol use, } \\
\text { perceived } \\
\text { health status } \\
\text { and baseline } \\
\text { CD4 count }\end{array}$ & $\begin{array}{l}\text { ART initiation } \\
\text { within 3- } \\
\text { months of } \\
\text { the staging } \\
\text { visit in } 81 \% \\
\text { overall. }\end{array}$ & $\begin{array}{l}\text { No association was observed } \\
\text { between depression and ART } \\
\text { initiation (RR: } 1.01 ; 95 \% \mathrm{Cl} \text { : } \\
0.87-1.17 \text { ). }\end{array}$ \\
\hline
\end{tabular}

AHR: Adjusted hazards ratio; AIDS: Acquired immunodeficiency syndrome; AOR: Adjusted odds ratio; APRR: Adjusted prevalence risk ratio; ARR: Adjusted relative risk; ART: Antiretroviral therapy; ARV: Antiretroviral; ASHR: Adjusted sub-hazard ratio; OR: Odds ratio; PICT: Provider initiated counselling and testing; RR: Relative risk; TB-Tuberculosis; VCT: Voluntary counselling and testing; WHO: World Health Organization

*Studies included in other categories 


\begin{tabular}{|c|c|c|c|c|c|c|c|}
\hline Author & Country & Population & $\begin{array}{l}\text { Study } \\
\text { Design }\end{array}$ & Measurement & $\begin{array}{l}\text { Types of } \\
\text { exposures }\end{array}$ & Findings & Conclusions \\
\hline $\begin{array}{l}\text { Gebru et al } \\
{[40]}\end{array}$ & Ethiopia & $\begin{array}{l}320 \text { HIV } \\
\text { infected } \\
\text { individuals }\end{array}$ & $\begin{array}{l}\text { Cohort } \\
\text { (2015- } \\
2016)\end{array}$ & $\begin{array}{l}\text { Cases: } 160 \\
\text { delayed ART } \\
\text { initiators } \\
\text { (CD4 count < } \\
350 \\
\text { cells/mm } \mathrm{mm}^{3} \text { or } \\
\text { WHO clinical } \\
\text { stage III/IV). } \\
\text { Controls: } 160 \\
\text { early ART } \\
\text { initiators } \\
\text { (CD4 count } \\
\geq 350 \\
\text { cells/mm } / \mathrm{mm}^{3} \text { or } \\
\text { WHO clinical } \\
\text { stage I/II). }\end{array}$ & $\begin{array}{l}\text { Gender, } \\
\text { marital } \\
\text { status, } \\
\text { education, } \\
\text { occupation, } \\
\text { wealth index, } \\
\text { length of time } \\
\text { lived with HIV, } \\
\text { knowledge } \\
\text { and } \\
\text { perception of } \\
\text { the } \\
\text { importance } \\
\text { of ART and } \\
\text { self-efficacy }\end{array}$ & $\begin{array}{l}\text { Person time } \\
\text { incidence } \\
\text { density of } \\
\text { ART } \\
\text { initiation: } \\
4.46 \text { per } 100 \\
\text { person- } \\
\text { months of } \\
\text { observation; } \\
\text { incidence } \\
\text { density of } \\
\text { delay in ART } \\
\text { initiation: } \\
2.21 \text { per } 100 \\
\text { person- } \\
\text { months. }\end{array}$ & $\begin{array}{l}\text { HIV care uninformed individuals } \\
\text { (OR:1.94; } 95 \% \mathrm{Cl}: 1.06-3.56 \text { ), } \\
\text { those who did not perceive } \\
\text { susceptibility to (OR: } 8.46 \text {; } \\
\text { 95\%Cl: } 3.92-18.26 \text { ) and severity } \\
\text { of the consequences of late ART } \\
\text { initiation (OR:6.13; } 95 \% \mathrm{Cl} \text { : } 2.95- \\
\text { 12.73), those who did not } \\
\text { believe in the health benefits of } \\
\text { ART (OR: } 3.12 ; 95 \% \mathrm{Cl}: 1.53- \\
\text { 6.33) and lack self-efficacy } \\
\text { (OR:2.35; } 95 \% C l: 1.09-5.05 \text { ) } \\
\text { had more likelihood of delayed } \\
\text { ART initiation. }\end{array}$ \\
\hline $\begin{array}{l}\text { *Kulkarni } \\
\text { et al [23] }\end{array}$ & Ethiopia & $\begin{array}{l}831 \text { HIV } \\
\text { infected } \\
\text { individuals } \\
\text { enrolled in } \\
\text { HIV care }\end{array}$ & $\begin{array}{l}\text { Cross- } \\
\text { sectional }\end{array}$ & $\begin{array}{l}\text { Time } \\
\text { between } \\
\text { enrolment in } \\
\text { care and ART } \\
\text { initiation }\end{array}$ & $\begin{array}{l}\text { Repeated } \\
\text { HIV-positive } \\
\text { testing }\end{array}$ & $\begin{array}{l}\text { Rate of ART } \\
\text { initiation: } \\
56.6 \% \text { within } \\
<30 \text { days in } \\
\text { single HIV- } \\
\text { positive } \\
\text { testers; } \\
46.4 \% \text { in } \\
\text { repeat HIV- } \\
\text { positive } \\
\text { testers. }\end{array}$ & $\begin{array}{l}\text { The median time of ART } \\
\text { initiation was significantly } \\
\text { longer in repeat HIV-positive } \\
\text { testers than single testers ( } 1.2 \\
\text { months; IQR: } 0.5-9.1 \text { months vs } \\
0.7 \text { months; IQR: } 0.5-9.2 \\
\text { months; } P<0.034) \text {. }\end{array}$ \\
\hline $\begin{array}{l}\text { Larsen et } \\
\text { al [55] }\end{array}$ & South Africa & $\begin{array}{l}6826 \text { ART } \\
\text { eligible } \\
\text { individuals }\end{array}$ & $\begin{array}{l}\text { Cross- } \\
\text { section }\end{array}$ & $\begin{array}{l}\text { Rate of ART } \\
\text { initiation } \\
\text { within } 14 \text { and } \\
60 \text { days of } \\
\text { treatment } \\
\text { eligibility }\end{array}$ & $\begin{array}{l}\text { Age, gender, } \\
\text { residence, } \\
\text { location of } \\
\text { health facility, } \\
\text { baseline CD4 } \\
\text { count, WHO } \\
\text { stage, } \\
\text { pregnancy } \\
\text { and TB co- } \\
\text { infection }\end{array}$ & $\begin{array}{l}\text { Rate of ART } \\
\text { initiation: } \\
53.6 \% \text { within } \\
14 \text { days and } \\
75.5 \% \text { within } \\
60 \text { days; } \\
\text { median time } \\
\text { of ART } \\
\text { initiation } 12 \\
\text { days. }\end{array}$ & 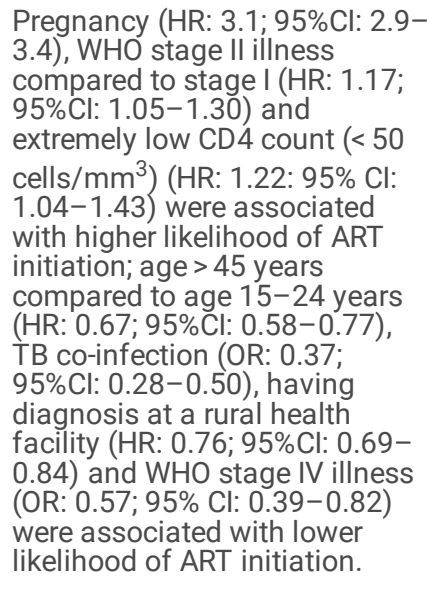 \\
\hline $\begin{array}{l}\text { *Maughan- } \\
\text { Brown et al } \\
{[56]}\end{array}$ & South Africa & $\begin{array}{l}58 \text { HIV } \\
\text { infected } \\
\text { individuals } \\
\text { linked to } \\
\text { care }\end{array}$ & $\begin{array}{l}\text { Cross- } \\
\text { sectional }\end{array}$ & $\begin{array}{l}\text { ART initiation } \\
\text { within 3- } \\
\text { months of } \\
\text { linkage to } \\
\text { care }\end{array}$ & $\begin{array}{l}\text { Readiness for } \\
\text { treatment, } \\
\text { alcohol use, } \\
\text { perceived } \\
\text { stigma, belief } \\
\text { about ARV } \\
\text { side-effects, } \\
\text { denial of } \\
\text { being HIV- } \\
\text { positive and } \\
\text { HIV status } \\
\text { disclosure }\end{array}$ & $\begin{array}{l}\text { Rate of ART } \\
\text { initiation in } \\
62 \% \text { overall. }\end{array}$ & $\begin{array}{l}\text { Readiness for treatment was } \\
\text { positively associated with ART } \\
\text { initiation (AOR: } 3.20 ; 95 \% \mathrm{Cl} \text { : } \\
1.09-9.39 \text { ) whereas alcohol use } \\
\text { (AOR: } 0.24 ; 95 \% \mathrm{Cl} \text { : } 0.08-0.73 \text { ) } \\
\text { and perceived stigma (AOR: } \\
0.20 ; 95 \% \mathrm{Cl} \text { : } 0.05-0.89 \text { ) were } \\
\text { negatively associated with ART } \\
\text { initiation. }\end{array}$ \\
\hline
\end{tabular}

AHR: Adjusted hazards ratio; AIDS: Acquired immunodeficiency syndrome; AOR: Adjusted odds ratio; APRR: Adjusted prevalence risk ratio; ARR: Adjusted relative risk; ART: Antiretroviral therapy; ARV: Antiretroviral; ASHR: Adjusted sub-hazard ratio; OR: Odds ratio; PICT: Provider initiated counselling and testing; RR: Relative risk; TB-Tuberculosis; VCT: Voluntary counselling and testing; WHO: World Health Organization

*Studies included in other categories 


\begin{tabular}{|c|c|c|c|c|c|c|c|}
\hline Author & Country & Population & $\begin{array}{l}\text { Study } \\
\text { Design }\end{array}$ & Measurement & $\begin{array}{l}\text { Types of } \\
\text { exposures }\end{array}$ & Findings & Conclusions \\
\hline $\begin{array}{l}\text { Nash et al } \\
{[10]}\end{array}$ & Ethiopia & $\begin{array}{l}1180 \text { HIV } \\
\text { infected } \\
\text { ART naïve } \\
\text { individuals }\end{array}$ & $\begin{array}{l}\text { Cross- } \\
\text { sectional }\end{array}$ & $\begin{array}{l}\text { Late ART } \\
\text { initiation } \\
\text { defined as } \\
\text { starting } \\
\text { treatment at } \\
\text { a CD } 4 \text { count } \\
\text { of }<150 \\
\text { cells } / \mathrm{mm}^{3} \text { or } \\
\text { WHO Stage } \\
\text { IV }\end{array}$ & $\begin{array}{l}\text { Age, gender, } \\
\text { education, } \\
\text { relationship } \\
\text { status, } \\
\text { alcohol use, } \\
\text { psychological } \\
\text { distress, } \\
\text { stigma, } \\
\text { history of } \\
\text { holy water } \\
\text { use for HIV, } \\
\text { residence, } \\
\text { knowing } \\
\text { someone on } \\
\text { ART, HIV } \\
\text { status } \\
\text { disclosure, } \\
\text { social } \\
\text { support and } \\
\text { reason for } \\
\text { HIV diagnosis }\end{array}$ & $\begin{array}{l}\text { Median time } \\
\text { between } \\
\text { enrolment in } \\
\text { care and ART } \\
\text { initiation } 2.9 \\
\text { months } \\
\text { overall; } 1.1 \\
\text { months in } \\
\text { women and } \\
5.3 \text { months } \\
\text { in men. }\end{array}$ & 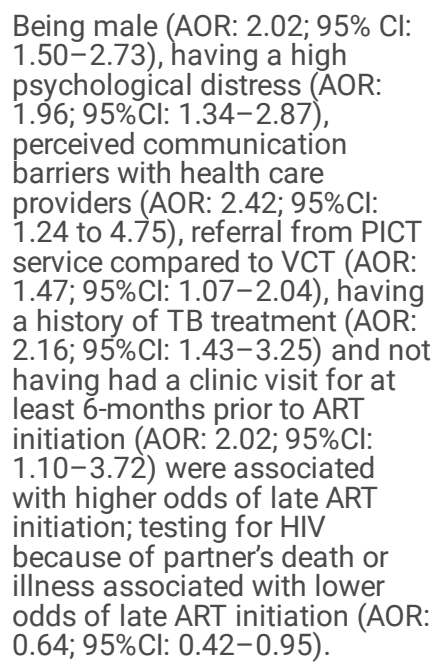 \\
\hline $\begin{array}{l}\text { *Teklu et al } \\
{[20]}\end{array}$ & Ethiopia & $\begin{array}{l}4159 \text { HIV } \\
\text { infected } \\
\text { individuals }\end{array}$ & $\begin{array}{l}\text { Cohort } \\
\text { (2005- } \\
2013)\end{array}$ & $\begin{array}{l}\text { Time from } \\
\text { eligibility for } \\
\text { ART (CD4 } \\
\text { count } \leq 500 \\
\text { cells/mm } 3 \text { or } \\
\text { WHO stage } \\
\text { III) to } \\
\text { treatment } \\
\text { initiation }\end{array}$ & $\begin{array}{l}\text { Age, gender, } \\
\text { baseline } \\
\text { WHO stage } \\
\text { and CD4 } \\
\text { count and } \\
\text { disclosure } \\
\text { status }\end{array}$ & $\begin{array}{l}\text { Rate of ART } \\
\text { initiation in } \\
48 \% \text { overall } \\
\text { within } 1- \\
\text { month of } \\
\text { eligibility. }\end{array}$ & $\begin{array}{l}\text { Lower risk of delayed ART } \\
\text { initiation was observed in older } \\
\text { adults (> } 24 \text { years) compared to } \\
\text { their younger counterparts ( } 15- \\
24 \text { years) (OR: } 0.77 ; 95 \% \mathrm{Cl}: \\
0.63-0.95 \text { ), in those who } \\
\text { enrolled within } 1 \text {-week of HIV } \\
\text { diagnosis compared to those } \\
\text { enrolled within }>1 \text { months (OR: } \\
0.79: 95 \% \mathrm{Cl}: 0.65-0.97) \text {, but a } \\
\text { higher risk in those who had a } \\
\text { higher baseline CD4 count }(\geq \\
100 \text { cells } / \mathrm{mm}^{3} \text { ) compared to < } \\
100 \text { cells } / \mathrm{mm}^{3} \text { (OR: } 1.15 ; 95 \% \mathrm{Cl} \text { : } \\
1.02-1.31) \text {. }\end{array}$ \\
\hline $\begin{array}{l}\text { Teasdale } \\
\text { et al [41] }\end{array}$ & Rwanda & $\begin{array}{l}31,033 \text { HIV } \\
\text { infected } \\
\text { ART naive } \\
\text { patients }\end{array}$ & $\begin{array}{l}\text { Cohort } \\
(2005- \\
2010)\end{array}$ & $\begin{array}{l}\text { Time from } \\
\text { eligibility for } \\
\text { ART ( } \leq 350 \\
\text { cells/mm } \mathrm{mm}^{3} \text { or } \\
\text { WHO stage } \\
\text { IV) to } \\
\text { treatment } \\
\text { initiation }\end{array}$ & $\begin{array}{l}\text { Age, gender, } \\
\text { point of entry } \\
\text { into care, CD } 4 \\
\text { count and } \\
\text { WHO stage at } \\
\text { eligibility and } \\
\text { facility type } \\
\text { and type of } \\
\text { setting }\end{array}$ & $\begin{array}{l}\text { Rate of ART } \\
\text { initiation in } \\
80 \% \text { overall } \\
\text { within } 12- \\
\text { months of } \\
\text { eligibility. }\end{array}$ & $\begin{array}{l}\text { Women (ASHR: } 0.8 ; 95 \% \mathrm{Cl}: 0.8- \\
0.9 \text { ), younger patients (15-20 } \\
\text { years of age) (ASHR: } 0.8 ; 95 \% \mathrm{Cl} \text { : } \\
0.8-0.9 \text { ) and those who enrolled } \\
\text { in care through inpatient wards } \\
\text { compared to VCT (ASHR: } 0.8 ; \\
95 \% \mathrm{Cl} \text { : } 0.7-0.9 \text { ) were less likely } \\
\text { to start ART; patients with a CD } 4 \\
\text { count of < } 200 \text { cells/mm } \mathrm{mm}^{3} \text { were } \\
\text { more likely to start ART } \\
\text { compared to CD } 4 \text { count > } 350 \\
\text { cells/mm } \mathrm{mm}^{3} \text { (ASHR: } 2.8 ; 95 \% \mathrm{Cl} \text { : } \\
1.7-4.5 \text { ). }\end{array}$ \\
\hline
\end{tabular}

AHR: Adjusted hazards ratio; AIDS: Acquired immunodeficiency syndrome; AOR: Adjusted odds ratio; APRR: Adjusted prevalence risk ratio; ARR: Adjusted relative risk; ART: Antiretroviral therapy; ARV: Antiretroviral; ASHR: Adjusted sub-hazard ratio; OR: Odds ratio; PICT: Provider initiated counselling and testing; RR: Relative risk; TB-Tuberculosis; VCT: Voluntary counselling and testing; WHO: World Health Organization

*Studies included in other categories 


\begin{tabular}{|c|c|c|c|c|c|c|c|}
\hline Author & Country & Population & $\begin{array}{l}\text { Study } \\
\text { Design }\end{array}$ & Measurement & $\begin{array}{l}\text { Types of } \\
\text { exposures }\end{array}$ & Findings & Conclusions \\
\hline $\begin{array}{l}\text { Plazy et al } \\
\text { [9] }\end{array}$ & South Africa & $\begin{array}{l}2243 \text { ART } \\
\text { eligible } \\
\text { people }\end{array}$ & $\begin{array}{l}\text { Cohort } \\
\text { (2007- } \\
2011)\end{array}$ & $\begin{array}{l}\text { ART initiation } \\
\text { within 3- } \\
\text { months of } \\
\text { eligibility }\end{array}$ & $\begin{array}{l}\text { Age, gender, } \\
\text { education, } \\
\text { occupation, } \\
\text { pregnancy, } \\
\text { residence, } \\
\text { economic } \\
\text { status, } \\
\text { household } \\
\text { wealth index, } \\
\text { distance to } \\
\text { the closest } \\
\text { clinic, } \\
\text { presence of a } \\
\text { household } \\
\text { member on } \\
\text { ART and CD4 } \\
\text { count }\end{array}$ & $\begin{array}{l}\text { Rate of ART } \\
\text { initiation in } \\
67 \% \text { overall; } \\
68.2 \% \text { in men } \\
\text { and } 60.2 \% \text { in } \\
\text { women. }\end{array}$ & 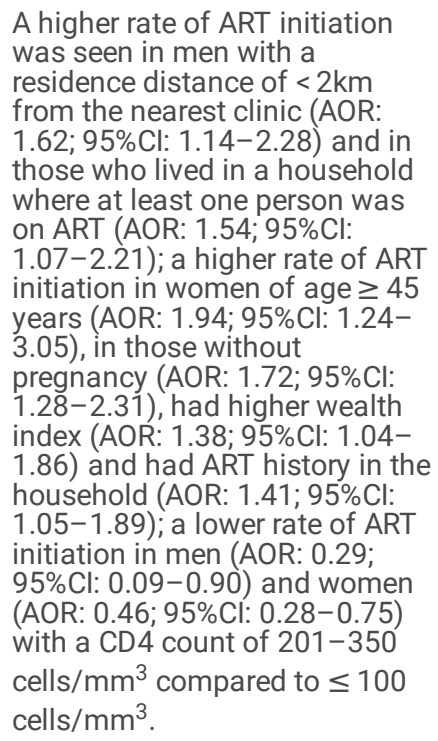 \\
\hline $\begin{array}{l}\text { Ogoina et } \\
\text { al [42] }\end{array}$ & Nigeria & $\begin{array}{l}186 \text { ART } \\
\text { ineligible } \\
\text { people at } \\
\text { enrolment } \\
\text { in care } \\
\text { (CD4 } \\
\text { count > } \\
350 \\
\text { cells/mm } / \mathrm{mm}^{3} \\
\text { and WHO } \\
\text { HIV stage } \\
\text { I/II) }\end{array}$ & $\begin{array}{l}\text { Cohort } \\
\text { (2008- } \\
2012)\end{array}$ & $\begin{array}{l}\text { Rate of ART } \\
\text { initiation } \\
\text { within } 48- \\
\text { months of } \\
\text { follow up }\end{array}$ & $\begin{array}{l}\text { Age, gender, } \\
\text { baseline } \\
\text { WHO stage } \\
\text { and CD4 } \\
\text { count }\end{array}$ & $\begin{array}{l}\text { Rate of ART } \\
\text { initiation in } \\
48.4 \% \\
\text { overall; } \\
\text { median time } \\
\text { of ART } \\
\text { initiation: } 18- \\
\text { months. }\end{array}$ & $\begin{array}{l}\text { Early ART initiation was } \\
\text { associated with stage-ll illness } \\
\text { (HR: } 2.30 ; 95 \% \mathrm{Cl}: 1.26-4.21) \\
\text { and a lower CD4 count (351- } \\
500 \text { cells/mm } \mathrm{mm}^{3} \text { (HR: } 1.70 \text {; } \\
95 \% \mathrm{Cl}: 1.01-2.98) .\end{array}$ \\
\hline $\begin{array}{l}\text { Odeny et al } \\
\text { [43] }\end{array}$ & Kenya & $\begin{array}{l}11,942 \text { HIV } \\
\text { infected } \\
\text { individuals } \\
\text { enrolled in } \\
\text { care }\end{array}$ & $\begin{array}{l}\text { Cohort } \\
\text { (2007- } \\
2012)\end{array}$ & $\begin{array}{l}\text { Initiating ART } \\
\text { within 2- } \\
\text { months of } \\
\text { eligibility for } \\
\text { ART }\end{array}$ & $\begin{array}{l}\text { Age, gender, } \\
\text { CD } 4 \text { count } \\
\text { and WHO } \\
\text { clinical stage } \\
\text { at the time of } \\
\text { eligibility, } \\
\text { type of health } \\
\text { facility, } \\
\text { volume of } \\
\text { patients } \\
\text { served in a } \\
\text { facility, } \\
\text { facility } \\
\text { location and } \\
\text { facility } \\
\text { ownership }\end{array}$ & $\begin{array}{l}\text { Rate of ART } \\
\text { initiation in } \\
75 \% \text { overall; } \\
\text { median time } \\
\text { of ART } \\
\text { initiation: } 1- \\
\text { month. }\end{array}$ & $\begin{array}{l}\text { A higher rate of ART initiation } \\
\text { was seen in patients with CD } 4 \\
\text { count of < } 200 \text { cells } / \mathrm{mm}^{3} \text { (HR: } \\
1.38 ; 95 \% \mathrm{Cl}: 1.23-1.55) \text { but } \\
\text { lower in those who were served } \\
\text { in a health facility with above } \\
\text { median patient volume (OR: } \\
0.57 ; 95 \% \mathrm{Cl}: 0.45-0.72) \text {. }\end{array}$ \\
\hline $\begin{array}{l}\text { Ngom et al } \\
\text { [14] }\end{array}$ & Senegal & $\begin{array}{l}3651 \text { HIV } \\
\text { infected } \\
\text { individuals } \\
\text { enrolled in } \\
\text { care }\end{array}$ & $\begin{array}{l}\text { Cohort } \\
\text { (1998- } \\
2015)\end{array}$ & $\begin{array}{l}\text { Time to } \\
\text { initiate ART } \\
\text { since } \\
\text { eligibility }\end{array}$ & $\begin{array}{l}\text { Age, gender, } \\
\text { marital } \\
\text { status, } \\
\text { occupation, } \\
\text { residence, } \\
\text { CD4 count, } \\
\text { WHO stage } \\
\text { and presence } \\
\text { of TB co- } \\
\text { infection }\end{array}$ & $\begin{array}{l}\text { Rate of ART } \\
\text { initiation in } \\
78 \% \text { overall } \\
\text { within 3- } \\
\text { months of } \\
\text { eligibility; } \\
\text { median time } \\
\text { to initiate } \\
\text { ART 2- } \\
\text { months. }\end{array}$ & $\begin{array}{l}\text { Lower enrolment CD4 count (< } \\
200 \text { cells/mm } \mathrm{mm}^{3} \text { ) and higher } \\
\text { WHO stage (III/IV) were } \\
\text { associated with more likelihood } \\
\text { of ART initiation (HR: } 3.5 ; 95 \% \mathrm{Cl} \text { : } \\
2.3-5.3) ; \text { patients with CD } 4 \\
\text { count of < } 200 \text { cells/mm } \mathrm{mm}^{3} \text { at } \\
\text { eligibility initiated ART with less } \\
\text { delay (HR: } 0.3 ; 95 \% \mathrm{Cl}: 0.2-0.6) \text {. }\end{array}$ \\
\hline
\end{tabular}

AHR: Adjusted hazards ratio; AIDS: Acquired immunodeficiency syndrome; AOR: Adjusted odds ratio; APRR: Adjusted prevalence risk ratio; ARR: Adjusted relative risk; ART: Antiretroviral therapy; ARV: Antiretroviral; ASHR: Adjusted sub-hazard ratio; OR: Odds ratio; PICT: Provider initiated counselling and testing; RR: Relative risk; TB-Tuberculosis; VCT: Voluntary counselling and testing; WHO: World Health Organization

*Studies included in other categories 


\begin{tabular}{|c|c|c|c|c|c|c|c|}
\hline Author & Country & Population & $\begin{array}{l}\text { Study } \\
\text { Design }\end{array}$ & Measurement & $\begin{array}{l}\text { Types of } \\
\text { exposures }\end{array}$ & Findings & Conclusions \\
\hline $\begin{array}{l}\text { *Franse et } \\
\text { al [66] }\end{array}$ & Rwanda & $\begin{array}{l}93 \text { ART } \\
\text { eligible } \\
\text { people }\end{array}$ & $\begin{array}{l}\text { Cluster non- } \\
\text { randomised } \\
\text { trial }\end{array}$ & $\begin{array}{l}\text { ART initiation } \\
\text { defined as } \\
\text { starting } \\
\text { treatment } \\
\text { within } 90 \\
\text { days of } \\
\text { diagnosis }\end{array}$ & $\begin{array}{l}\text { Age, gender } \\
\text { and } \\
\text { department } \\
\text { where } \\
\text { diagnosis } \\
\text { made }\end{array}$ & $\begin{array}{l}\text { Rate of ART } \\
\text { initiation in } \\
51.6 \% \\
\text { overall; } \\
\text { median time } \\
\text { between HIV } \\
\text { diagnosis } \\
\text { and start of } \\
\text { ART: } 35.5- \\
\text { days. }\end{array}$ & - \\
\hline $\begin{array}{l}\text { *Billioux et } \\
\text { al [46] }\end{array}$ & Uganda & $\begin{array}{l}3666 \text { HIV } \\
\text { infected } \\
\text { individuals }\end{array}$ & $\begin{array}{l}\text { Cohort } \\
(2013- \\
2015)\end{array}$ & $\begin{array}{l}\text { ART initiation } \\
\text { defined as } \\
\text { having a } \\
\text { clinically } \\
\text { confirmed } \\
\text { ART initiation } \\
\text { date and/or } \\
\text { self-reported } \\
\text { use } \\
\text { of ART }\end{array}$ & $\begin{array}{l}\text { Age, gender, } \\
\text { education, } \\
\text { marital } \\
\text { status, } \\
\text { religion, } \\
\text { occupation, } \\
\text { income and } \\
\text { community } \\
\text { type }\end{array}$ & $\begin{array}{l}\text { ART initiation } \\
\text { in } 63 \% \\
\text { overall. }\end{array}$ & $\begin{array}{l}\text { Males (APRR: } 0.75 ; 95 \% \mathrm{Cl} \text { : } \\
0.69-0.82) \text {, people of younger } \\
\text { age groups (age } 15-24 \text { years) } \\
\text { (APRR: } 0.69 ; 95 \% \mathrm{Cl}: 0.60-0.80 \text { ) } \\
\text { and those who had never } \\
\text { married (APRR: } 0.80 ; 95 \% \mathrm{Cl} \text { : } \\
0.66-0.95 \text { ) were less likely to } \\
\text { use ART. }\end{array}$ \\
\hline $\begin{array}{l}\text { Hoffman } \\
\text { et al [51] }\end{array}$ & Ethiopia & $\begin{array}{l}1180 \text { HIV } \\
\text { infected } \\
\text { individuals }\end{array}$ & $\begin{array}{l}\text { Cross- } \\
\text { sectional }\end{array}$ & $\begin{array}{l}\text { Late ART } \\
\text { initiation } \\
\text { defined as } \\
\text { CD4 count < } \\
150 \\
\text { cells/mm } \mathrm{mm}^{3} \text { or } \\
\text { WHO stage IV } \\
\text { at ART } \\
\text { initiation }\end{array}$ & $\begin{array}{l}\text { Internalized, } \\
\text { anticipated } \\
\text { and enacted } \\
\text { stigma }\end{array}$ & - & $\begin{array}{l}\text { All the three domains of stigma } \\
\text { were not associated with late } \\
\text { ART initiation. }\end{array}$ \\
\hline $\begin{array}{l}\text { *Lopez- } \\
\text { Varela et al } \\
{[49]}\end{array}$ & Mozambique & $\begin{array}{l}338 \text { ART } \\
\text { eligible } \\
\text { patients }\end{array}$ & $\begin{array}{l}\text { Cohort } \\
(2014- \\
2015)\end{array}$ & $\begin{array}{l}\text { ART initiation } \\
\text { within 3- } \\
\text { months of } \\
\text { eligibility } \\
\text { (CD } 4 \text { count > } \\
350 \\
\text { cells } / \mathrm{mm}^{3} \text { ) }\end{array}$ & $\begin{array}{l}\text { Age, gender } \\
\text { and testing } \\
\text { modality }\end{array}$ & $\begin{array}{l}\text { ART initiation } \\
\text { in } 83.7 \% \\
\text { overall; } \\
\text { median time } \\
\text { to initiate } \\
\text { ART since } \\
\text { diagnosis: } 46 \\
\text { days. }\end{array}$ & $\begin{array}{l}\text { Age and testing modality were } \\
\text { not associated with ART } \\
\text { initiation. }\end{array}$ \\
\hline $\begin{array}{l}\text { *Rentsch } \\
\text { et al [12] }\end{array}$ & Tanzania & $\begin{array}{l}95 \text { HIV } \\
\text { infected } \\
\text { individuals } \\
\text { linked to } \\
\text { care }\end{array}$ & $\begin{array}{l}\text { Cohort } \\
(2014- \\
2017)\end{array}$ & $\begin{array}{l}\text { ART initiation } \\
\text { within } 3,6 \\
\text { and } 12- \\
\text { months of } \\
\text { linkage to } \\
\text { care }\end{array}$ & $\begin{array}{l}\text { Age, gender } \\
\text { and residence }\end{array}$ & $\begin{array}{l}\text { ART initiation } \\
80.9 \%, 86.8 \% \\
\text { and } 94.1 \% \\
\text { within } 3,6 \\
\text { and } 12- \\
\text { months of } \\
\text { linkage to } \\
\text { care } \\
\text { respectively } \\
\text { in individuals } \\
\text { diagnosed } \\
\text { using facility- } \\
\text { based } \\
\text { approaches; } \\
63 \%, 77.8 \% \\
\text { and } 85.2 \% \\
\text { within } 3,6 \\
\text { and } 12- \\
\text { months } \\
\text { respectively } \\
\text { in individuals } \\
\text { diagnosed } \\
\text { using } \\
\text { community- } \\
\text { based sero- } \\
\text { survey. }\end{array}$ & $\begin{array}{l}\text { There was no statistically } \\
\text { significant association between } \\
\text { testing modality and ART } \\
\text { initiation. }\end{array}$ \\
\hline
\end{tabular}

AHR: Adjusted hazards ratio; AIDS: Acquired immunodeficiency syndrome; AOR: Adjusted odds ratio; APRR: Adjusted prevalence risk ratio; ARR: Adjusted relative risk; ART: Antiretroviral therapy; ARV: Antiretroviral; ASHR: Adjusted sub-hazard ratio; OR: Odds ratio; PICT: Provider initiated counselling and testing; RR: Relative risk; TB-Tuberculosis; VCT: Voluntary counselling and testing; WHO: World Health Organization

*Studies included in other categories 


\begin{tabular}{|c|c|c|c|c|c|c|c|}
\hline Author & Country & Population & $\begin{array}{l}\text { Study } \\
\text { Design }\end{array}$ & Measurement & $\begin{array}{l}\text { Types of } \\
\text { exposures }\end{array}$ & Findings & Conclusions \\
\hline $\begin{array}{l}\text { Anlay et al } \\
\text { [62] }\end{array}$ & Ethiopia & $\begin{array}{l}410 \text { HIV } \\
\text { infected } \\
\text { individuals } \\
\text { initiating } \\
\text { ART }\end{array}$ & $\begin{array}{l}\text { Cross- } \\
\text { sectional }\end{array}$ & $\begin{array}{l}\text { Late ART } \\
\text { initiation } \\
\text { defined as } \\
\text { having a CD4 } \\
\text { count } \leq 200 \\
\text { cells/mm } \mathrm{mm}^{3} \\
\text { and/or AIDS } \\
\text { defining } \\
\text { illness }\end{array}$ & $\begin{array}{l}\text { Age, gender, } \\
\text { education, } \\
\text { marital } \\
\text { status, } \\
\text { religion, } \\
\text { occupation, } \\
\text { residence, } \\
\text { HIV status } \\
\text { disclosure, } \\
\text { functional } \\
\text { status, } \\
\text { baseline CD4 } \\
\text { count and } \\
\text { WHO stage, } \\
\text { length of time } \\
\text { between HIV } \\
\text { testing and } \\
\text { enrolment in } \\
\text { care, } \\
\text { substance } \\
\text { use and } \\
\text { medication } \\
\text { before ART }\end{array}$ & $\begin{array}{l}\text { Late ART } \\
\text { initiation in } \\
67.3 \% \\
\text { overall. }\end{array}$ & $\begin{array}{l}\text { People in the age group of } 35 \text { to } \\
44 \text { years (AOR: } 3.85 ; 95 \% \mathrm{Cl} \text { : } \\
1.68-8.82) \text {, those who were } \\
\text { unmarried } \\
\text { (AOR: } 1.88 ; 95 \% \mathrm{Cl}: 1.13-3.03 \text { ) } \\
\text { and bedridden (AOR: } 4.68 ; \\
95 \% \mathrm{Cl}: 1.49-14.68 \text { ) were more } \\
\text { likely to initiate ART late. }\end{array}$ \\
\hline $\begin{array}{l}\text { Esber et al } \\
\text { [63] }\end{array}$ & $\begin{array}{l}\text { Uganda, } \\
\text { Kenya, } \\
\text { Tanzania } \\
\text { and Nigeria }\end{array}$ & $\begin{array}{l}2888 \text { HIV } \\
\text { infected } \\
\text { individuals }\end{array}$ & $\begin{array}{l}\text { Cross- } \\
\text { sectional }\end{array}$ & $\begin{array}{l}\text { Time to ART } \\
\text { initiation } \\
\text { since } \\
\text { diagnosis }\end{array}$ & $\begin{array}{l}\text { Age, gender, } \\
\text { education } \\
\text { and baseline } \\
\text { CD4 count }\end{array}$ & - & $\begin{array}{l}\text { The hazards of initiating ART } \\
\text { was lower in individuals with a } \\
\text { higher CD } 4 \text { count ( } \geq 500 \\
\left.\text { cells } / \mathrm{mm}^{3}\right) \text { (AHR: } \\
0.32 ; 95 \% \mathrm{Cl}: 0.28 \text { to } 0.37) \text { and } \\
\text { those in the age group of } 18 \text { to } \\
29 \text { years. }\end{array}$ \\
\hline $\begin{array}{l}\text { Katz et al } \\
{[52]}\end{array}$ & South Africa & $\begin{array}{l}500 \text { HIV } \\
\text { infected } \\
\text { individuals }\end{array}$ & $\begin{array}{l}\text { Cohort } \\
(2014- \\
2015)\end{array}$ & $\begin{array}{l}\text { ART initiation } \\
\text { within 6- } \\
\text { months of } \\
\text { diagnosis }\end{array}$ & $\begin{array}{l}\text { Social } \\
\text { support and } \\
\text { coping } \\
\text { strategies }\end{array}$ & $\begin{array}{l}\text { ART initiation } \\
\text { in } 62 \% \\
\text { overall. }\end{array}$ & $\begin{array}{l}\text { Using substance use as a } \\
\text { coping mechanism was } \\
\text { associated with lower odds of } \\
\text { ART initiation (AOR: } 0.79 ; 95 \% \mathrm{Cl} \text { : } \\
0.65-0.97 \text { ). }\end{array}$ \\
\hline $\begin{array}{l}\text { Lilian et al } \\
\text { [64] }\end{array}$ & South Africa & $\begin{array}{l}32290 \text { HIV } \\
\text { infected } \\
\text { individuals }\end{array}$ & $\begin{array}{l}\text { Cross- } \\
\text { sectional }\end{array}$ & $\begin{array}{l}\text { Initiation of } \\
\text { ART on the } \\
\text { date of } \\
\text { diagnosis }\end{array}$ & $\begin{array}{l}\text { Age, gender, } \\
\text { baseline CD } 4 \\
\text { count and } \\
\text { WHO stage }\end{array}$ & $\begin{array}{l}\text { ART initiation } \\
\text { in } 40.4 \% \\
\text { overall; } 30 \% \\
\text { in males and } \\
45.7 \% \text { in } \\
\text { females. }\end{array}$ & $\begin{array}{l}\text { ART initiators were younger } \\
\text { (median age = } 31.9 \text { years), } \\
\text { females and people with less } \\
\text { advanced HIV infection (CD } 4> \\
100 \text { cells } / \mathrm{mm}^{3} \text { and/or WHO } \\
\text { stage I/II). }\end{array}$ \\
\hline $\begin{array}{l}\text { Onoya et } \\
\text { al [53] }\end{array}$ & South Africa & $\begin{array}{l}1029 \text { HIV } \\
\text { infected } \\
\text { individuals }\end{array}$ & $\begin{array}{l}\text { Cohort } \\
(2015- \\
2018)\end{array}$ & $\begin{array}{l}\text { ART initiation } \\
\text { on the date } \\
\text { of diagnosis } \\
\text { and within } 30 \\
\text { days }\end{array}$ & $\begin{array}{l}\text { Age, gender, } \\
\text { education, } \\
\text { marital } \\
\text { status, } \\
\text { employment, } \\
\text { baseline CD4 } \\
\text { count, } \\
\text { number of } \\
\text { adults in a } \\
\text { household } \\
\text { and a travel } \\
\text { time to a } \\
\text { clinic }\end{array}$ & $\begin{array}{l}\text { ART initiation } \\
\text { on the date } \\
\text { of diagnosis } \\
\text { in } 20.2 \% \\
\text { overall; } \\
71.9 \% \text { within } \\
30 \text { days. }\end{array}$ & $\begin{array}{l}\text { Women were more likely to take } \\
\text { up ART on the diagnosis date } \\
\text { (ARR: } 1.3 ; 95 \% \text { Cl: } 1.0-1.9 \text { ) and } \\
\text { had a higher rate of } 30 \text {-day ART } \\
\text { initiation (AHR: } 1.2 ; 95 \% C l: 1.0 \\
-1.4 \text { ) compared to males; living } \\
\text { in a two-adult home increased } \\
\text { the rate of } 30 \text {-day ART initiation } \\
\text { compared to living alone (AHR: } \\
1.2 ; 95 \% \mathrm{Cl}: 1.0-1.5 \text { ); older } \\
\text { participants (age } \geq 40 \text { years) } \\
\text { were less likely to take up ART } \\
\text { on the diagnosis date (ARR: } 0.6 \text {; } \\
\text { 95\%Cl: } 0.4-0.9 \text { ) compared to } \\
\text { patients in the } 18-24 \text { age } \\
\text { group. }\end{array}$ \\
\hline \multicolumn{8}{|c|}{$\begin{array}{l}\text { AHR: Adjusted hazards ratio; AIDS: Acquired immunodeficiency syndrome; AOR: Adjusted odds ratio; APRR: Adjusted prevalence risk ratio; ARR: } \\
\text { Adjusted relative risk; ART: Antiretroviral therapy; ARV: Antiretroviral; ASHR: Adjusted sub-hazard ratio; OR: Odds ratio; PICT: Provider initiated } \\
\text { counselling and testing; RR: Relative risk; TB-Tuberculosis; VCT: Voluntary counselling and testing; WHO: World Health Organization }\end{array}$} \\
\hline
\end{tabular}

Six studies determined the rate of ART initiation at various time intervals after treatment eligibility $[9,14,20,41,43,55]$; within one, two and three months. The rate varied from $41 \%$ in Rwanda to $48 \%$ in Ethiopia within the first month [20, 41], 75\% both in Kenya and South Africa within the second month [43, 55], and from $67 \%$ in South Africa to $78 \%$ in Senegal within the third month $[14,65]$.

Various factors were reported to influence ART initiation, some of which were akin to those influencing linkage to care. Eight studies identified service delivery factors as barriers to ART initiation $[9,10,13,40,41,43,49]$. Relative to diagnosis in voluntary counselling and testing (VCT) services, lower 
odds of ART initiation were reported in PLWH who were diagnosed at health care facilities with a high volume of patients, and in those who enrolled in care through inpatient wards and provider initiated counselling and testing (PICT) services [10, 41, 43]. While Brown et al [13] found a lower likelihood of initiating ART in PLWH who were diagnosed through community-based approaches compared to health facility-based approaches, Lopez-Varela et al [49] and Rentsch et al [12] identified no association between a testing modality and ART initiation. A lower likelihood of ART initiation was reported in PLWH residing more than $2 \mathrm{~km}$ away from the nearest health care facility, in those who experienced perceived communication barriers with health care providers, and in those with low awareness about HIV care $[9,10,40]$.

Eight studies reported behavioural or psychosocial factors relating to ART initiation $[9,10,23,40,52,53,56,65]$. A lack of perceived susceptibility to, and understanding of the severity of, the consequences of late treatment, as well as a lack of belief in the health benefits of early treatment predisposed PLWH to delayed ART initiation [40]. Testing that was undertaken due to symptoms, and patients readiness to commence treatment, were positively associated with ART initiation [10,56], however patient desire for repeated testing was found to predict delayed ART initiation [23]. Nash et al [10] found an association between psychological distress and delayed ART initiation, but Cholera et al [54] reported no association between these variables. While using any substance as a coping mechanism decreased the odds of ART initiation [52], PLWH who reported drinking alcohol were $76 \%$ less likely to initiate ART than those who did not [56].

Factors related to social support (such as having a regular partner, living in a two-adult household and the presence of another household member taking ART) were positively associated with ART initiation $[53,65]$. Perceived social stigma and failure to disclose HIV status predicted delayed ART initiation [56] although this finding has been contradicted by another study [51].

Fourteen studies identified clinical findings as risk factors for delayed ART initiation [9, 10, 13, 14, 20, 39, 41-43, 55, 62-65]. A lower baseline CD4 count ( $<500$ cells $/ \mathrm{mm}^{3}$ ) and higher WHO clinical stages (III/IV) were positively associated with ART initiation [9, 13, 14, 20, 39, 41-43, 55, 63, 65], whereas the presence of TB co-infection and being a bedridden patient was found to negatively predict ART initiation [10, 55, 62]. Nonetheless, in a study that assessed same day treatment [64], ART initiators had a significantly less advanced HIV infection (CD4 count > 100cells/mm ${ }^{3}$ and/or WHO stage I/II) compared to non-initiators.

Twelve studies identified sociodemographic characteristics including: age, gender, marital status and wealth index as predictors of ART initiation [9, $10,20,39,41,46,53,55,62-65]$. Most studies analysing the influence of age on ART initiation reported younger age (below 25 years) as a risk factor for delayed ART initiation $[20,39,41,46,63,65]$. However, older PLWH ( $\geq 40$ years of age) were less likely to take up same day ART compared to their younger counterparts [53,64]. Similarly, except a study by Teasdale et al [41] in Rwanda, studies reported lower odds of ART initiation (including same day ART) in males than females [10,46,53]. An increased likelihood of ART initiation was reported in married PLWH and in those who had a higher wealth index $[9,46,62]$.

\section{Meta-analyses of factors affecting linkage to HIV care and ART initiation}

Eighteen studies involving a combined total of 27,396 people were included in the meta-analyses to assess factors affecting linkage to care and ART initiation. People in younger age groups (<35 years) were 29\% (Fig. 2a; OR: 0.71; 95\%Cl: 0.55-0.91, I² = 74\%) and 45\% (Fig. 2b; OR: 0.55; 95\%Cl: $0.49-0.63, \mathrm{I}^{2}=0 \%$ ) less likely to be linked to care and initiate ART respectively compared to older age groups ( $\geq 35$ years). A study by Anlay et al [62] was removed from the analysis of the effect of age on ART initiation because of a high level of heterogeneity.

Employed people and people who travelled for more than an hour to reach a clinic were more than 1.3 (Fig. 3a; OR: 1.32; 95\%Cl: 1.14-1.52, $\mathrm{I}^{2}=14 \%$ ) and 1.2 (Fig. 3b; OR: 1.27 ; 95\% Cl: $1.15-1.39, \mathrm{I}^{2}=57 \%$ ) times more likely to be presented late for care, respectively. A study by Lifson et al [59] was excluded from the analysis of employment and presentation for care due to a high level of heterogeneity.

The likelihood of linkage to care decreased by $26 \%$ (Fig. $4 \mathrm{a}$; OR: $0.74 ; 95 \% \mathrm{Cl}: 0.62-0.87, \mathrm{I}^{2}=25 \%$ ) in people who were unable to disclose their HIV status and by $50 \%$ (Fig. 4 b; OR: $0.50 ; 95 \% \mathrm{Cl}: 0.42-0.60, \mathrm{I}^{2}=0 \%$ ) in those who had a baseline CD 4 count $>350$ cells $/ \mathrm{mm}^{3}$ compared to CD 4 count $\leq$ 350 cells $/ \mathrm{mm}^{3}$, but increased by $65 \%$ (Fig. 4c; OR: $1.65 ; 95 \% \mathrm{Cl}: 1.16-2.34, \mathrm{I}^{2}=0 \%$ ) in those who were diagnosed through health facility-based testing approaches compared to community-based approaches. Studies by Rentsch et al [12] and Sanga et al [45] were excluded from the analysis of a testing modality and linkage to care due to a high level of heterogeneity.

\section{Discussion}

Timely initiation of ART is essential to prevent AIDS and non-AIDS related comorbidities and mortality [2, 3], as well as reducing the likelihood of new HIV infections $[4,5]$. This review demonstrated substantial disparities in the rates of linkage to HIV care and ART initiation across nations in SSA and between settings within a given nation. Overall, care linkage and treatment initiation rates are considerably low in most settings as compared to the second target of UNAIDS 95-95-95 goal, which aims to initiate treatment in 95\% of HIV infected individuals [71]. Through the literature synthesis, we identified healthcare delivery (structural), psychosocial, behavioural and sociodemographic factors as determinants of late linkage to care and delayed ART initiation amongst HIV infected adults in SSA.

Structural factors

Page 18/28 
Our meta-analyses identified distance to ART sites as the main risk factor for late linkage to care in SSA countries. Similar findings have been reported by a previous review in which transport costs associated with distant ART clinics was the most cited barrier to care in the region [32]. Although PLWH tend to engage in care more when it is easily accessible [9], many PLWH in SSA may be required to travel long distances, sometimes on foot, to access HIV care due to shortage of transport or associated costs [16,30]. This could be a major concern for low wealth index PLWH households, and partially explain why they are less likely to be linked to HIV care and commence treatment. There have been substantial expansions of ART services in the region in recent years, yet only a few public health care facilities provide the services at a district level [72], underscoring the need for the use of optimal task shifting $[73,74]$ and service integration strategies [75] to reach all people who need treatment.

This systematic review and meta-analyses showed that PLWH initiate ART late when enrolled at clinics with a high volume of patients and diagnosed through community-based counselling and testing approaches. Community-based HIV testing approaches have substantially increased the number of people eligible for ART in SSA [72]. However, insufficiency of appropriately trained staff continues to be a main challenge to initiate treatment in all infected individuals [76]. Studies show that the more PLWH are satisfied with pre-ART care and understand the information given by service providers, the greater the likelihood of ART initiation $[10,43,77]$. In contrast, when clinic operating hours are not well tailored with PLWH's daily routines, timely clinic visits diminish, which leads to delays in treatment commencement [24]. This may help to explain why employed individuals are more likely to be linked to care late relative to their unemployed counterparts, as demonstrated from our meta-analyses. Enhancing after-hours services and workplace programs may help combat this problem, as would providing ART training for lower level health care staff [78, 79].

\section{Psychosocial factors}

HIV status disclosure was significantly associated with an increased likelihood of linkage to care in the current meta-analyses, which is concordant with prior reviews conducted in SSA [30,32]. Status disclosure enables PLWH to access social support which reduces the negative influence of social stigma, one of the barriers to accessing care in this review $[17,31]$. This is evidenced by the finding that married PLWH and those who lived with adults (particularly with those who use ART) are more likely to commence treatment. Conversely, failure to disclose HIV status increases the likelihood of care disengagement during pre-ART period [22]. Expansion of the social networks of PLWH is important in this regard in addition to provision of appropriate counselling support, particularly for newly-diagnosed individuals [80].

Findings regarding the effect of psychological distress on ART initiation were equivocal in our review. Previous studies have shown that the prevalence of depression is generally higher in HIV infection, and both pre- and post-HIV diagnosis depression may affect an individual's ability to seek or access regular care [54, 81, 82]. Depressed PLWH are also at particular risk for substance misuse, which can lead to late care engagement [81, 83]. Interventions aiming at integrating diagnosis and treatment of depression with HIV care may help improve ART initiation in this important population group.

Perceptions related to clinical conditions

Our review showed that clinical circumstances such as having a higher baseline CD4 count (> 350 cells $/ \mathrm{mm}^{3}$ ) and lower levels of WHO defined clinical stages are associated with late linkage to care and delayed ART initiation. This is consistent with a narrative review conducted previously in the region, which reported initiation of ART at a very low CD4 count in most PLWH [30]. At asymptomatic stages of HIV infection (i.e., at high CD4 count and low WHO clinical stages), PLWH often feel healthy and may perceive that they do not need treatment [19, 31]. During these stages, PLWH may also hesitate to accept a HIV positive diagnosis, thus requiring repeated testing that can lead to delayed linkage to care [10]. However, the current review also demonstrated that HIV-related symptoms alone may not always be sufficient to prompt ART initiation, but patient readiness and confidence that the treatment is safe and efficient is also required. Structural factors related to prioritisation of the sickest patients, and low absorptive capacity of health care facilities may also contribute to initiation of ART at low CD4 count in SSA [30]. The rapid expansion of the program in the region may hopefully mitigate these structural barriers [72] yet increasing PLWH's awareness of the health benefits of early ART initiation remains critical in ensuring treatment initiation in all infected individuals [6].

TB co-infected and bed-restricted PLWH are less likely to be linked to care and initiate ART. In spite of HIV/TB treatment guidelines' recommendation to initiate ART after the commencement of TB treatment [84], PLWH with TB co-infection may be concerned about adverse drug interactions, pill burden and drug side-effects, and therefore forgo initiation of ART $[85,86]$. PLWH may also be unable to attend clinic appointments due to severe medical conditions associated with the advancement of the disease.

Other behavioural factors

Using positive reframing as a coping strategy was found to be associated with a high rate of linkage to care. This is consistent with previous findings that showed the positive impact of a desire for good health on care engagement [87]. PLWH with such forethought commence ART hoping that their general health would be improved because opportunistic diseases could be prevented, which could also ultimately minimise social stigma due to HIV-related illnesses [18].

Sociodemographic factors 
In this review, males and younger PLWH (below 35 years of age) are more at risk of late linkage to care and delayed ART initiation compared to females and PLWH of older age groups (35 years and above) respectively. The lower rates of linkage to care and ART initiation in males and younger PLWH in the current review support findings of previous reviews conducted in SSA [30, 32]. PLWH of younger age groups are known to have low awareness of their HIV status, and are more likely to experience and adversely react to stigmatisation, as well as engage in substance use [88], which is a significant predictor of delayed ART initiation in the current review. Moreover, younger PLWHA struggle with disclosure of their HIV status which may lead to limited access to information and material supports [89, 90].

Contextual and cultural norms related to masculinity can play a strong part in hampering health seeking behaviour in males [31, 91]. Females tend to be more engaged in health care systems through programs focusing on maternal health. Therefore, adaptation of health services and treatment options to the needs of men and younger people may help close the gaps in linkage to care and ART initiation.

In interpreting the findings of this review, the following important limitations should be considered. The included studies represent only a few nations of SSA, which restricts the generalisability of the findings. Representativeness is also restricted due to the wide variability of outcomes across geographical locations. Because most studies used a retrospective cohort or a cross-sectional design, causality between the exposure variables and the outcomes cannot be assured even though important risk factors for late linkage to care and delayed ART initiation have been adequately explored. Rates of linkage to care and ART initiation were measured at varying lengths of time using different reference points, which impacted the development of precise estimation of the outcomes. However, relatively more inclusive measures were taken to embrace a range of results in the analysis. As there has not been a standardised definition for delayed ART initiation, the included studies defined the outcome differently, following the available treatment eligibility guidelines within a particular period of time. To minimise this discrepancy, we used the highest and lowest cut points to ensure generalisability of the findings to all included studies. In addition to substantial heterogeneity between studies in effect measures (with respect to some of the exposure variables), only $54 \%$ of the included studies were scored at moderate or above in the overall quality assessment, which may lower the quality of evidence. Although the review used a systematic search strategy, there exists a possibility of missing relevant studies because screening was undertaken by a single reviewer and unpublished data were not explored. Due to time and resource constraints, we included only studies published in English language which may increase the risk of publication bias, and we did not report a funnel plot due to the small number of studies $(n<10)$ included in the analysis for each exposure variable [92]. Finally, despite efforts in this regard, we were not able to contact authors of primary studies regarding incomplete data, which restricted the analysis of factors for delayed ART initiation.

\section{Conclusions}

This systematic review and meta-analyses identified a range of risk factors for late linkage to care and delayed ART initiation amongst HIV infected adults in SSA, which included: health service delivery, psychosocial, behavioural and sociodemographic circumstances. We recommend implementation of patient-centred intervention approaches to alleviate barriers and to reinforce best practices and lessons learned from high achieving settings to those with particular challenges.

\section{Abbreviations}

AHR: Adjusted hazards ratio; AIDS: Acquired immunodeficiency syndrome; APRR: Adjusted prevalence risk ratio; ART: Antiretroviral therapy; ARVs: Antiretrovirals; CD4: cluster of differentiation-4; Cl: Confidence interval; EPHPP: Effective public health practice project; HIV: Human immunodeficiency virus; OR: odds ratio; PICT: Provider initiated counselling and testing; PLWH: People living with HIV; PRISMA: Preferred reporting items for systematic reviews and meta-analyses; PROSPERO: Prospective register of systematic reviews; RR: Relative risk; SSA: sub-Saharan Africa; TB: tuberculosis; USD: United States dollars; VCT: Voluntary counselling and testing; UNAIDS: The Joint United Nations Programme on HIV/AIDS; WHO: World Health Organization

\section{Declarations}

\section{Ethics approval and consent to participate}

Not applicable

\section{Consent for publication}

Not applicable

\section{Availability of data and materials}

The datasets used and/or analysed during the current study are available from the corresponding author on reasonable request.

\section{Competing interests}

The authors declare that they have no competing interests. 


\section{Funding}

Not applicable.

\section{Authors' contributions}

TGF developed the search strategy; conducted searching, screening of the articles, data extraction and analysis; drafted the manuscript. ERM participated in the quality assessment of the studies and subsequent revisions of the manuscript; GT contributed to and reviewed the manuscript.

\section{Acknowledgements}

We would like to acknowledge Mr Tariku Laelago and Mr Tadele Yohannes for assessing the quality of included studies.

\section{References}

1. Trickey A, May M, Vehreschild JJ, Obel N, Gill M, Crane H, et al. Survival of HIV-positive patients starting antiretroviral therapy between 1996 and 2013: a collaborative analysis of cohort studies. Lancet HIV. 2017;4:e349-56.

2. Lundgren JD, Babiker AG, Gordin F, Emery S, Grund B, Sharma S, et al. Initiation of Antiretroviral Therapy in Early Asymptomatic HIV Infection. The New England Journal of Medicine. 2015;373(9):795-807.

3. Granich R, Gupta S, Hersh B, Williams B, Montaner J, Young B, et al. Trends in AIDS Deaths, New Infections and ART Coverage in the Top 30 Countries with the Highest AIDS Mortality Burden: 1990-2013. PLoS One. 2015;10(7):e0131353.

4. Cohen MS, Chen YQ, McCauley M, Gamble T, Hosseinipour MC, Kumarasamy N, et al. Antiretroviral Therapy for the Prevention of HIV-1 Transmission. The New England Journal of Medicine. 2016;375(9):830-9.

5. Na H, Song D, Yingying D, Keming R, Jennifer MM, Manhong J, et al. Antiretroviral therapy reduces HIV transmission in discordant couples in rural Yunnan, China. PLoS ONE. 2013;8(11):e77981.

6. WHO. Guideline on when to start antiretroviral therapy and on pre-exposure prophylaxis for HIV. Geneva, Switzerland: World Health Organization (WHO); 2015.

7. Fomundam HN, Tesfay AR, Mushipe SA, Mosina MB, Boshielo CT, Nyambi HT, et al. Prevalence and predictors of late presentation for HIV care in South Africa. South African medical journal = Suid-Afrikaanse tydskrif vir geneeskunde. 2017;107(12):1058-64.

8. van der Kop ML, Thabane L, Awiti PO, Muhula S, Kyomuhangi LB, Lester RT, et al. Advanced HIV disease at presentation to care in Nairobi, Kenya: late diagnosis or delayed linkage to care?-a cross-sectional study. BMC infectious diseases. 2016;16.

9. Plazy M, Newell ML, Orne-Gliemann J, Naidu K, Dabis F, Dray-Spira R. Barriers to antiretroviral treatment initiation in rural KwaZulu-Natal, South Africa. HIV medicine. 2015;16(9):521-32.

10. Nash D, Tymejczyk O, Gadisa T, Kulkarni SG, Hoffman S, Yigzaw M, et al. Factors associated with initiation of antiretroviral therapy in the advanced stages of HIV infection in six Ethiopian HIV clinics, 2012 to 2013. Journal of the International AIDS Society. 2016;19(1):20637.

11. Gesesew HA, Ward P, Woldemichael K, Mwanri L. Late presentation for HIV care in Southwest Ethiopia in 2003-2015: prevalence, trend, outcomes and risk factors. BMC infectious diseases. 2018;18(1):59.

12. Rentsch CT, Wringe A, Machemba R, Michael D, Urassa M, Todd J, et al. Linkage to care and antiretroviral therapy initiation by testing modality among individuals newly diagnosed with HIV in Tanzania, 2014-2017. Tropical medicine \& international health : TM \& IH. 2018;23(12):1384-93.

13. Brown JP, Ngwira B, Tafatatha T, Crampin AC, French N, Koole O. Determinants of time to antiretroviral treatment initiation and subsequent mortality on treatment in a cohort in rural northern Malawi. AIDS Research \& Therapy [Electronic Resource]. 2016;13:24.

14. Ngom NF, Faye MA, Ndiaye K, Thiam A, Ndour CT, Etard JF, et al. ART initiation in an outpatient treatment center in Dakar, Senegal: A retrospective cohort analysis (1998-2015). PLoS ONE [Electronic Resource]. 2018;13(9):e0202984.

15. Kwobah CM, Braitstein P, Koech JK, Simiyu G, Mwangi AW, Wools-Kaloustian K, et al. Factors Associated with Late Engagement to HIV Care in Western Kenya: A Cross-Sectional Study. Journal of the International Association of Providers of AIDS Care. 2016;15(6):505-11.

16. Yakob B, Ncama BP. A socio-ecological perspective of access to and acceptability of HIV/AIDS treatment and care services: A qualitative case study research. BMC public health. 2016;16(1):155.

17. Dorward J, Mabuto T, Charalambous S, Fielding KL, Hoffmann CJ. Factors Associated With Poor Linkage to HIV Care in South Africa: Secondary Analysis of Data From the Thol'impilo Trial. Journal of acquired immune deficiency syndromes (1999). 2017;76(5):453-60.

18. Lambert RF, Orrell C, Bangsberg DR, Haberer JE. Factors that Motivated Otherwise Healthy HIV-Positive Young Adults to Access HIV Testing and Treatment in South Africa. AIDS \& Behavior. 2018;22(3):733-41.

19. Reddy EA, Agala CB, Maro VP, Ostermann J, Pence BW, Itemba DK, et al. Test site predicts HIV care linkage and antiretroviral therapy initiation: a prospective 3.5 year cohort study of HIV-positive testers in northern Tanzania. BMC infectious diseases. 2016;16:497.

20. Teklu AM, Delele K, Abraha M, Belayhun B, Gudina EK, Nega A. Exploratory Analysis of Time from HIV Diagnosis to ART Start, Factors and effect on survival: A longitudinal follow up study at seven teaching hospitals in Ethiopia. Ethiopian journal of health sciences. 2017;27(Suppl 1):17-28. 
21. Camlin CS, Neilands TB, Odeny TA, Lyamuya R, Nakiwogga-Muwanga A, Diero L, et al. Patient-reported factors associated with reengagement among HIV-infected patients disengaged from care in East Africa. AIDS (London, England). 2016;30(3):495-502.

22. Shaweno T, Shaweno D. When are patients lost to follow-up in pre-antiretroviral therapy care? A retrospective assessment of patients in an Ethiopian rural hospital. Infectious diseases of poverty. 2015;4(1):27.

23. Kulkarni S, Tymejczyk O, Gadisa T, Lahuerta M, Remien RH, Melaku Z, et al. "Testing, Testing": Multiple HIV-Positive Tests among Patients Initiating Antiretroviral Therapy in Ethiopia. Journal of the International Association of Providers of AIDS Care. 2017;16(6):546-54.

24. da Silva M, Blevins M, Wester CW, Manjolo J, Jose E, Gonzalez LC, et al. Patient loss to follow-up before antiretroviral therapy initiation in rural Mozambique. AIDS and behavior. 2015;19(4):666-78.

25. Castelnuovo B, Musaazi J, Musomba R, Ratanshi R, Kiragga AN. Quantifying retention during pre-antiretroviral treatment in a large urban clinic in Uganda. BMC infectious diseases. 2015;15(1):252.

26. Maman D, Ben-Farhat J, Chilima B, Masiku C, Salumu L, Ford N, et al. Factors associated with HIV status awareness and Linkage to Care following home based testing in rural Malawi. Tropical medicine \& international health : TM \& IH. 2016;21(11):1442-51.

27. Maheu-Giroux M, Tanser F, Boily MC, Pillay D, Joseph SA, Barnighausen T. Determinants of time from HIV infection to linkage-to-care in rural KwaZulu-Natal, South Africa. AIDS (London, England). 2017;31(7):1017-24.

28. Govindasamy D, Meghij J, Kebede Negussi E, Clare Baggaley R, Ford N, Kranzer K. Interventions to improve or facilitate linkage to or retention in pre-ART (HIV) care and initiation of ART in low- and middle-income settings - a systematic review. Journal of the International AIDS Society. 2014;17:19032.

29. Fox MP, Rosen S, Geldsetzer P, Bärnighausen T, Negussie E, Beanland R. Interventions to improve the rate or timing of initiation of antiretroviral therapy for HIV in sub-Saharan Africa: meta-analyses of effectiveness. Journal of the International AIDS Society. 2016;19(1):20888.

30. Lahuerta M, Ue F, Hoffman S, Elul B, Kulkarni SG, Wu Y, et al. The Problem of Late ART Initiation in Sub-Saharan Africa: A Transient Aspect of Scale-up or a Long-term Phenomenon? . J Health Care Poor Underserved. 2013;24(1):359-83.

31. Ahmed S, Autrey J, Katz IT, Fox MP, Rosen S, Onoya D, et al. Why do people living with HIV not initiate treatment? A systematic review of qualitative evidence from low- and middle-income countries. Social science \& medicine (1982). 2018;213:72-84.

32. Govindasamya D, Fordb N, Kranzerd K. Risk factors, barriers and facilitators for linkage to antiretroviral therapy care: a systematic review. AIDS (London, England). 2012;26(16):2059-67.

33. Page MJ, McKenzie JE, Bossuyt PM, Boutron I, Hoffmann TC, Mulrow CD, et al. The PRISMA 2020 statement: an updated guideline for reporting systematic reviews. BMJ. 2021;372:71.

34. Fuge TG, Tsourtos G, Miller ER. A systematic review and meta-analyses on risk factors for late linkage to care and delayed antiretroviral therapy initiation amongst HIV infected adults in sub-Saharan Africa: a review protocol. PROSPERO. 2021;Protocol number: CRD42021264398.

35. Borenstein M, Hedges L, Rothstein H. Meta-Analysis: Fixed effect vs. random effects. 2007.

36. Tufanaru C, Munn Z, Stephenson M, Aromataris E. Fixed or random effects meta-analysis? Common methodological issues in systematic reviews of effectiveness. International Journal of Evidence-Based Healthcare. 2015;13(3):196-207.

37. Higgins JPT, Thompson SG, Deeks JJ, Altman DG. Measuring inconsistency in meta-analyses.(Education and debate). British Medical Journal. 2003,327(7414):557.

38. Review Manager (RevMan) [Computer program]. Version 53 Copenhagen: The Nordic Cochrane Centre, The Cochrane Collaboration; 2014.

39. Bor J, Chiu C, Ahmed S, Katz I, Fox MP, Rosen S, et al. Failure to initiate HIV treatment in patients with high CD4 counts: evidence from demographic surveillance in rural South Africa. Tropical medicine \& international health : TM \& IH. 2018;23(2):206-20.

40. Gebru T, Lentiro K, Jemal A. Perceived behavioural predictors of late initiation to HIV/AIDS care in Gurage zone public health facilities: a cohort study using health belief model. BMC research notes. 2018;11(1):336.

41. Teasdale CA, Wang CH, Francois U, Ndahimana JD, Vincent M, Sahabo R, et al. Time to Initiation of Antiretroviral Therapy Among Patients Who Are ART Eligible in Rwanda: Improvement Over Time. Jaids-Journal of Acquired Immune Deficiency Syndromes. 2015;68(3):314-21.

42. Ogoina D, Finomo F, Harry T, Inatimi O, Ebuenyi I, Tariladei WW, et al. Factors Associated with Timing of Initiation of Antiretroviral Therapy among HIV-1 Infected Adults in the Niger Delta Region of Nigeria. PloS one. 2015;10(5):e0125665.

43. Odeny TA, DeCenso B, Dansereau E, Gasasira A, Kisia C, Njuguna P, et al. The clock is ticking: the rate and timeliness of antiretroviral therapy initiation from the time of treatment eligibility in Kenya. Journal of the International AIDS Society. 2015;18:20019.

44. Luma HN, Jua P, Donfack OT, Kamdem F, Ngouadjeu E, Mbatchou HB, et al. Late presentation to HIV/AIDS care at the Douala general hospital, Cameroon: its associated factors, and consequences. BMC infectious diseases. 2018;18(1):298.

45. Sanga ES, Lerebo W, Mushi AK, Clowes P, Olomi W, Maboko L, et al. Linkage into care among newly diagnosed HIV-positive individuals tested through outreach and facility-based HIV testing models in Mbeya, Tanzania: a prospective mixed-method cohort study. BMJ open. 2017;7(4):e013733.

46. Billioux VG, Chang LW, Reynolds SJ, Nakigozi G, Ssekasanvu J, Grabowski MK, et al. Human immunodeficiency virus care cascade among subpopulations in Rakai, Uganda: An observational study: An: Journal of the International AIDS Society. 20 (1) (no pagination), 2017. Article

Page $22 / 28$ 
Number: 21590. Date of Publication: 2017.; 2017.

47. Boeke CE, Nabitaka V, Rowan A, Guerra K, Kabbale A, Asire B, et al. Assessing linkage to and retention in care among HIV patients in Uganda and identifying opportunities for health systems strengthening: a descriptive study. BMC infectious diseases. 2018;18(1):138.

48. Honge BL, Jespersen S, Aunsborg J, Mendes DV, Medina C, da Silva Te D, et al. High prevalence and excess mortality of late presenters among HIV-1, HIV-2 and HIV-1/2 dually infected patients in Guinea-Bissau - a cohort study from West Africa. The Pan African medical journal. 2016;25:40.

49. Lopez-Varela E, Fuente-Soro L, Augusto OJ, Sacoor C, Nhacolo A, Karajeanes E, et al. Continuum of HIV Care in Rural Mozambique: The Implications of HIV Testing Modality on Linkage and Retention. Jaids-Journal of Acquired Immune Deficiency Syndromes. 2018;78(5):527-35.

50. Rane MS, Hong T, Govere S, Thulare H, Moosa MY, Celum C, et al. Depression and Anxiety as Risk Factors for Delayed Care-Seeking Behavior in Human Immunodeficiency Virus-Infected Individuals in South Africa. Clinical Infectious Diseases. 2018;67(9):1411-8.

51. Hoffman S, Tymejczyk O, Kulkarni S, Lahuerta M, Gadisa T, Remien RH, et al. Stigma and HIV Care Continuum Outcomes Among Ethiopian Adults Initiating ART. Jaids-Journal of Acquired Immune Deficiency Syndromes. 2017;76(4):382-7.

52. Katz IT, Bogart LM, Dietrich JJ, Leslie HH, lyer HS, Leone D, et al. Understanding the role of resilience resources, antiretroviral therapy initiation, and HIV-1 RNA suppression among people living with HIV in South Africa: a prospective cohort study. AIDS (London, England). 2019;33 Suppl 1:S71-S9.

53. Onoya D, Sineke T, Hendrickson C, Mokhele I, Maskew M, Long LC, et al. Impact of the test and treat policy on delays in antiretroviral therapy initiation among adult HIV positive patients from six clinics in Johannesburg, South Africa: results from a prospective cohort study. BMJ open. 2020;10(3):e030228.

54. Cholera R, Pence BW, Gaynes BN, Bassett J, Qangule N, Pettifor A, et al. Depression and Engagement in Care Among Newly Diagnosed HIVInfected Adults in Johannesburg, South Africa. AIDS and behavior. 2017;21(6):1632-40.

55. Larsen A, Cheyip M, Tesfay A, Vranken P, Fomundam H, Wutoh A, et al. Timing and Predictors of Initiation on Antiretroviral Therapy Among Newly-Diagnosed HIV-Infected Persons in South Africa. AIDS \& Behavior. 2019;23(2):375-85.

56. Maughan-Brown B, Harrison A, Galarraga O, Kuo C, Smith P, Bekker LG, et al. Factors affecting linkage to HIV care and ART initiation following referral for ART by a mobile health clinic in South Africa: evidence from a multimethod study. Journal of Behavioral Medicine. 2019;11:11.

57. Takah N, Awungafac G, Aminde L, Ali I, Ndasi J, Njukeng P. Delayed entry into HIV care after diagnosis in two specialized care and treatment centres in Cameroon: the influence of CD4 count and WHO staging. BMC public health. 2016;16:n/a.

58. Kayabu DE, Ngocho JS, Mmbaga BT. Effective linkage from point of HIV testing to care and treatment in Tanga region, Tanzania. PloS one. 2018;13(8):e0201644.

59. Lifson AR, Workneh S, Hailemichael A, MacLehose RF, Horvath KJ, Hilk R, et al. Advanced HIV Disease among Males and Females Initiating HIV Care in Rural Ethiopia. Journal of the International Association of Providers of AIDS Care. 2019;18:2325958219847199.

60. Maughan-Brown B, Beckett S, Kharsany ABM, Cawood C, Khanyile D, Lewis L, et al. Poor rates of linkage to HIV care and uptake of treatment after home-based HIV testing among newly diagnosed 15-to-49 year-old men and women in a high HIV prevalence setting in South Africa. AIDS care. 2021;33(1):70-9.

61. Haskew J, Turner K, Rø G, Ho A, Kimanga D, Sharif S. Stage of HIV presentation at initial clinic visit following a community-based HIV testing campaign in rural Kenya. BMC public health. 2015;15:16.

62. Anlay DZ, Tiruneh BT, Dachew BA. Late ART Initiation among adult HIV patients at university of Gondar Hospital, NorthWest Ethiopia. African health sciences. 2019;19(3):2324-34.

63. Esber AL, Coakley P, Ake JA, Bahemana E, Adamu Y, Kiweewa F, et al. Decreasing time to antiretroviral therapy initiation after HIV diagnosis in a clinic-based observational cohort study in four African countries. Journal of the International AIDS Society. 2020;23(2):e25446.

64. Lilian RR, Rees K, McIntyre JA, Struthers HE, Peters RPH. Same-day antiretroviral therapy initiation for HIV-infected adults in South Africa: Analysis of routine data. PloS one. 2020;15(1):e0227572.

65. Boyer S, Iwuji C, Gosset A, Protopopescu C, Okesola N, Plazy M, et al. Factors associated with antiretroviral treatment initiation amongst HIVpositive individuals linked to care within a universal test and treat programme: early findings of the ANRS 12249 TasP trial in rural South Africa. AIDS care. 2016;28(3):39-51.

66. Franse CB, Kayigamba FR, Bakker MI, Mugisha V, Bagiruwigize E, Mitchell KR, et al. Linkage to HIV care before and after the introduction of provider-initiated testing and counselling in six Rwandan health facilities. AIDS care. 2017;29(3):326-34.

67. Gelaw YA, Senbete GH, Adane AA, Alene KA. Determinants of late presentation to HIV/AIDS care in Southern Tigray Zone, Northern Ethiopia: an institution based case-control study. Aids Research and Therapy. 2015;12.

68. Moreira AL, Fronteira I, Augusto GF, Martins MR. Unmatched Case-Control Study on Late Presentation of HIV Infection in Santiago, Cape Verde (2004-2011). International journal of environmental research and public health. 2016;13(3).

69. Nyika H, Mugurungi O, Shambira G, Gombe NT, Bangure D, Mungati M, et al. Factors associated with late presentation for HIV/AIDS care in Harare City, Zimbabwe, 2015. BMC public health. 2016;16:369.

Page 23/28 
70. Hoffman S, Leu CS, Ramjee G, Blanchard K, Gandhi AD, O'Sullivan L, et al. Linkage to Care Following an HIV Diagnosis in Three Public Sector Clinics in eThekwini (Durban), South Africa: Findings from a Prospective Cohort Study. AIDS and behavior. 2020;24(4):1181-96.

71. UNAIDS. Understanding Fast-Track: Accelerating Actions to end the AIDS Epidemic by 2030. Geneva, Switzerland: Joint United Nations Programme on HIV/AIDS; 2015.

72. UNAIDS. Joint United Nations Programme on HIV/AIDS (UNAIDS) data for 2020. Geneva, Switzerland: UNAIDS; 2020.

73. Crowley T, Mayers P. Trends in task shifting in HIV treatment in Africa: Effectiveness, challenges and acceptability to the health professions. African Journal of Primary Health Care and Family Medicine. 2015;7(1).

74. Boulle C, Kouanfack C, Laborde-Balen G, Carrieri MP, Dontsop M, Boyer S, et al. Task shifting HIV care in rural district hospitals in Cameroon: evidence of comparable antiretroviral treatment-related outcomes between nurses and physicians in the Stratall ANRS/ESTHER trial. Journal of Acquired Immune Deficiency Syndromes: JAIDS.62(5):569-76.

75. Topp SM, Chipukuma JM, Giganti M, Mwango LK, Chiko LM, Tambatamba-Chapula B, et al. Strengthening health systems at facility-level: Feasibility of integrating antiretroviral therapy into primary health care services in Lusaka, Zambia. PLoS One. 2010;5(7):e11522-e.

76. Baine S, Kasangaki A. A scoping study on task shifting the case of Uganda. BMC Health Services Research. 2014;14(1):184.

77. Loeliger KB, Niccolai LM, Mtungwa LN, Moll A, Shenoi SV. Antiretroviral therapy initiation and adherence in rural South Africa: community health workers' perspectives on barriers and facilitators. AIDS care. 2016;28(8):982-93.

78. Asiimwe S, Ross JM, Arinaitwe A, Tumusiime O, Turyamureeba B, Roberts DA, et al. Expanding HIV testing and linkage to care in southwestern Uganda with community health extension workers.(Research article). Journal of the International AIDS Society. 2017;20(S4):80.

79. Mwai GW, Mburu G, Torpey K, Frost P, Ford N, Seeley J. Role and outcomes of community health workers in HIV care in sub-Saharan Africa: a systematic review. Journal of the International AIDS Society. 2013;16:18586.

80. Salmen CR, Hickey MD, Fiorella KJ, Omollo D, Ouma G, Zoughbie D, et al. "Wan Kanyakla" (We are together): Community transformations in Kenya following a social network intervention for HIV care. Social science \& medicine (1982). 2015;147:332-40.

81. Bhatia R, Hartman C, Kallen M, Graham J, Giordano T. Persons Newly Diagnosed with HIV Infection are at High Risk for Depression and Poor Linkage to Care: Results from the Steps Study. AIDS and Behavior. 2011;15(6):1161-70.

82. Tegger M, Crane H, Tapia K, Uldall K, Holte S, Kitahata M. The Effect of Mental Illness, Substance Use, and Treatment for Depression on the Initiation of Highly Active Aritiretroviral Therapy among HIV-Infected Individuals. AIDS Patient Care \& STDs. 2008;22(3):233.

83. Gardner IL, Metsch RL, Anderson-Mahoney MP, Loughlin DA, Rio LC, Strathdee AS, et al. Efficacy of a brief case management intervention to link recently diagnosed HIV-infected persons to care. AIDS (London, England). 2005;19(4):423-31.

84. WHO. Treatment of tuberculosis: guidelines for national programmes. Geneva: World Health Organization (WHO); 2003.

85. Chilton D, Edwards SG, Pellegrino P, Miller RF. Factors influencing delay in initiating antiretroviral therapy among HIV infected patients coinfected with tuberculosis. Thorax. 2008;63(10):935.

86. Maponga BA, Chirundu D, Gombe NT, Tshimanga M, Bangure D, Takundwa L. Delayed initiation of anti-retroviral therapy in TB/HIV co-infected patients, Sanyati District, Zimbabwe, 2011-2012. The Pan African medical journal. 2015;21:28.

87. Garrett N, Norman E, Leask K, Naicker N, Asari V, Majola N, et al. Acceptability of Early Antiretroviral Therapy Among South African Women. AIDS \& Behavior. 2018;22(3):1018-24.

88. UNICEF, UNAIDS, WHO. Young People and HIV/AIDS; Opportunity in Crisis Switzerland: United Nations Children's Fund (UNICEF); 2002.

89. Kenu E, Obo-Akwa A, Nuamah G, Brefo A, Sam M, Lartey M. Knowledge and disclosure of HIV status among adolescents and young adults attending an adolescent HIV clinic in Accra, Ghana. BMC Research Notes. 2014;7(1):844.

90. Greenhalgh C, Evangeli M, Frize G, Foster C, Fidler S. Intimate relationships in young adults with perinatally acquired HIV: a qualitative study of strategies used to manage HIV disclosure. AIDS Care. 2016;28(3):283-8.

91. Skovdal M, Campbell C, Madanhire C, Mupambireyi Z, Nyamukapa C, Gregson S. Masculinity as a barrier to men's use of HIV services in Zimbabwe. Globalization and health. 2011;7(1):13.

92. Sedgwick P, Marston L. How to read a funnel plot in a meta-analysis. BMJ : British Medical Journal. 2015;351:h4718.

\section{Figures}




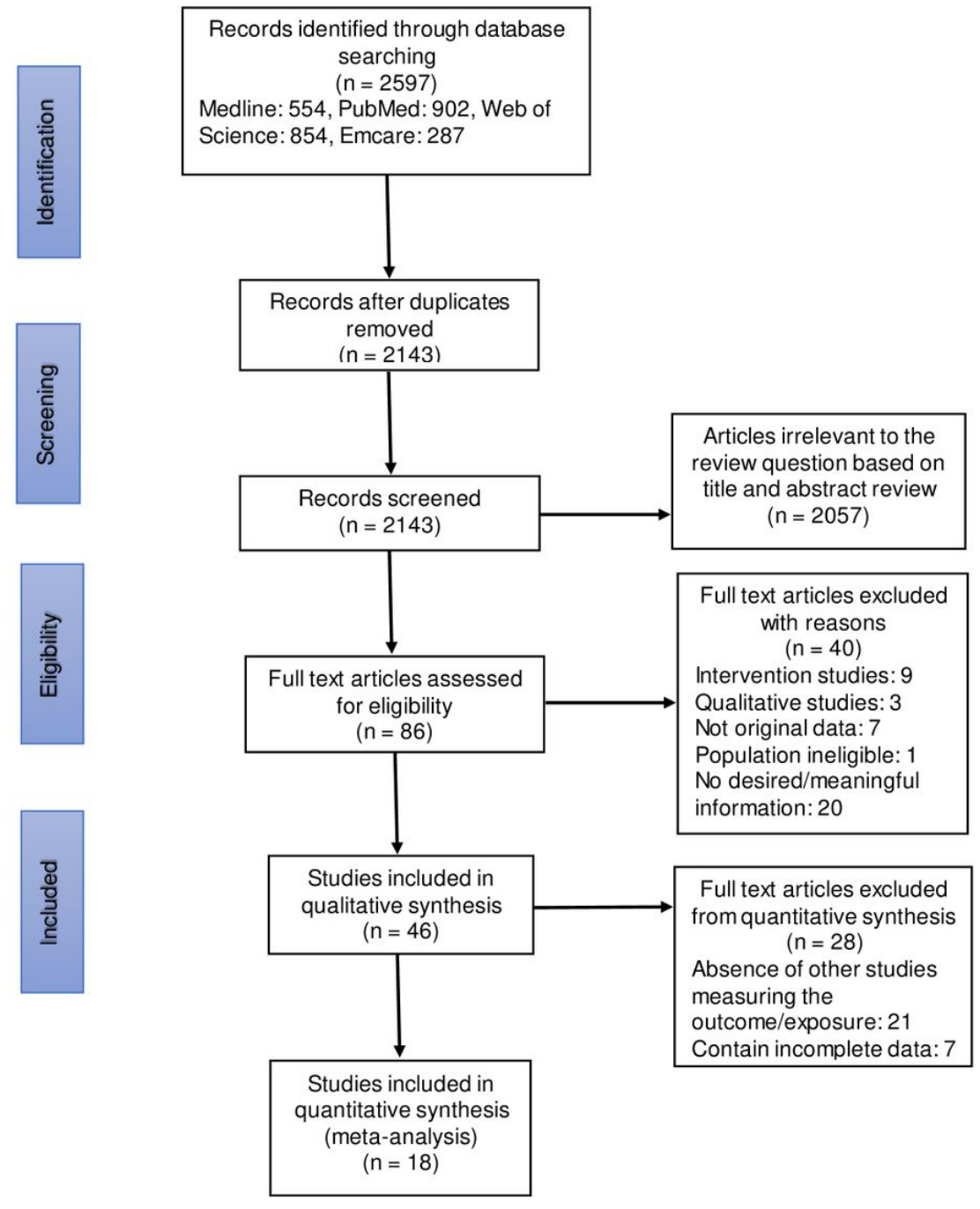

Figure 1

Study flow diagram. Study selection process and reasons for exclusion. 
Age $<35$ years Age $\geq 35$ years

Events Total Events

Study or Subgroup

Billioux et al 2017

Dorward et al 2017

Franse et al 2017

Kayabu 2018

Lopez-Varela et al 2018

Maughan-Brown 2019

Rentsch et al 2018

Total $(95 \% \mathrm{Cl})$

Total events

Heterogeneity: $\operatorname{Tau}^{2}=0.07 ; \mathrm{Chi}^{2}=22.73, \mathrm{df}=6(\mathrm{P}=0.0009) ; 1^{2}=74 \%$

Test for overall effect: $Z=2.67(P=0.008)$

2040
Odds Ratio

$\begin{array}{llllll}2101 & 2929 & 628 & 737 & 19.0 \% & 0.44[0.35,0.55]\end{array}$

$\begin{array}{llllll}768 & 1796 & 333 & 602 & 19.8 \% & 0.60[0.50,0.73]\end{array}$

$\begin{array}{llllll}150 & 414 & 82 & 212 & 15.8 \% & 0.90[0.64,1.27]\end{array}$

$\begin{array}{lllll}301 & 327 & 718 & 769 & 12.0 \%\end{array}$

$\begin{array}{lllll}259 & 401 & 231 & 320 & 16.4 \%\end{array}$

$\begin{array}{lllll}42 & 63 & 16 & 23 & 4.7 \%\end{array}$

$\begin{array}{lllll}66 & 267 & 32 & 144 & 12.3 \%\end{array}$

$6197 \quad 2807 \quad 100.0 \%$

a)

\section{Age $<35$ years Age $\geq 35$ years}

Events Total Events

Study or Subgroup

Anlay et al 2019

Billioux et al 2017

Franse et al 2017

Lopez-Varela et al 2018

Plazy 2015

Total $(95 \% \mathrm{Cl})$

Total events

Heterogeneity: Tau $^{2}=0.00 ; \mathrm{Chi}^{2}=1.02, \mathrm{df}=3(P=0.80) ; 1^{2}=0 \%$

Test for overall effect: $Z=9.50(P<0.00001)$

\section{Odds Ratio}

Total Weight $\mathrm{M}-\mathrm{H}$, Random, $95 \% \mathrm{Cl}$
Odds Ratio

$\mathrm{M} \cdot \mathrm{H}$, Random, $95 \% \mathrm{Cl}$

$0.82[0.50,1.34]$

$0.70[0.51,0.97]$

$0.88[0.31,2.45]$

$1.15[0.71,1.86]$

$0.71[0.55,0.91]$

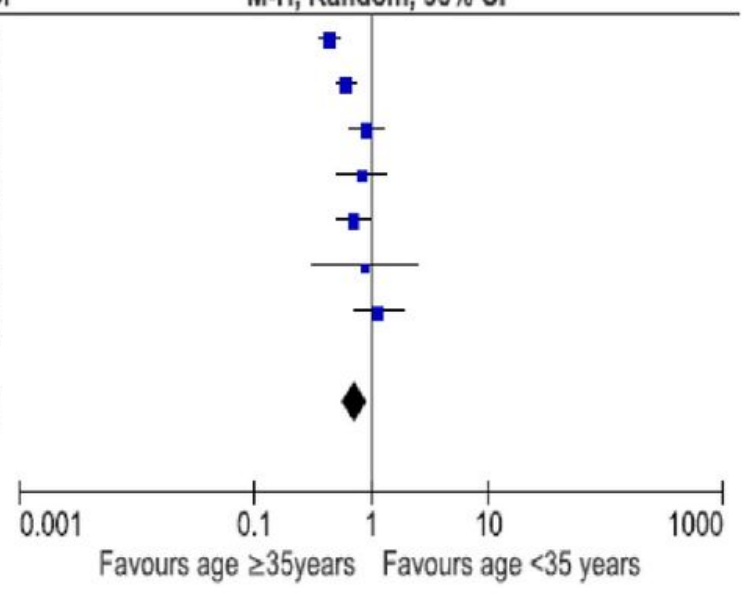

b)

Figure 2

Forest plot of associations between linkage to care and age (a), and ART initiation (b). Lower likelihood of linkage to care and ART initiation in people in younger age groups ( $<35$ years). 


\section{Employed Unemployed}

Odds Ratio

Study or Subgroup Events Total Events Total Weight $\mathrm{M} \cdot \mathrm{H}, \mathrm{Random}, 95 \% \mathrm{Cl}$

\begin{tabular}{|c|c|c|c|c|c|}
\hline Gelaw 2015 & 123 & 235 & 68 & 133 & $10.5 \%$ \\
\hline Kwobah 2016 & 540 & 1939 & 1858 & 8508 & $69.6 \%$ \\
\hline Lifson et al 2019 & 782 & 1332 & 131 & 179 & $0.0 \%$ \\
\hline Luma 2018 & 1150 & 1271 & 522 & 595 & $18.5 \%$ \\
\hline Reddy 2016 & 36 & 224 & 4 & 16 & $1.5 \%$ \\
\hline Total $(95 \% \mathrm{Cl})$ & \multicolumn{3}{|c|}{3669} & 9252 & 100.0 \\
\hline Total events & 1849 & & 2452 & & \\
\hline \multicolumn{6}{|c|}{ Heterogeneity: $\operatorname{Tau}^{2}=0.00 ; \mathrm{Chi}^{2}=3.50, d f=3(P=0.32) ; 1^{2}=14 \%$} \\
\hline \multicolumn{6}{|c|}{ Test for overall effect: $Z=3.74(P=0.0002)$} \\
\hline
\end{tabular}

a)
Odds Ratio

$\mathrm{M} \cdot \mathrm{H}$, Random, $95 \% \mathrm{Cl}$

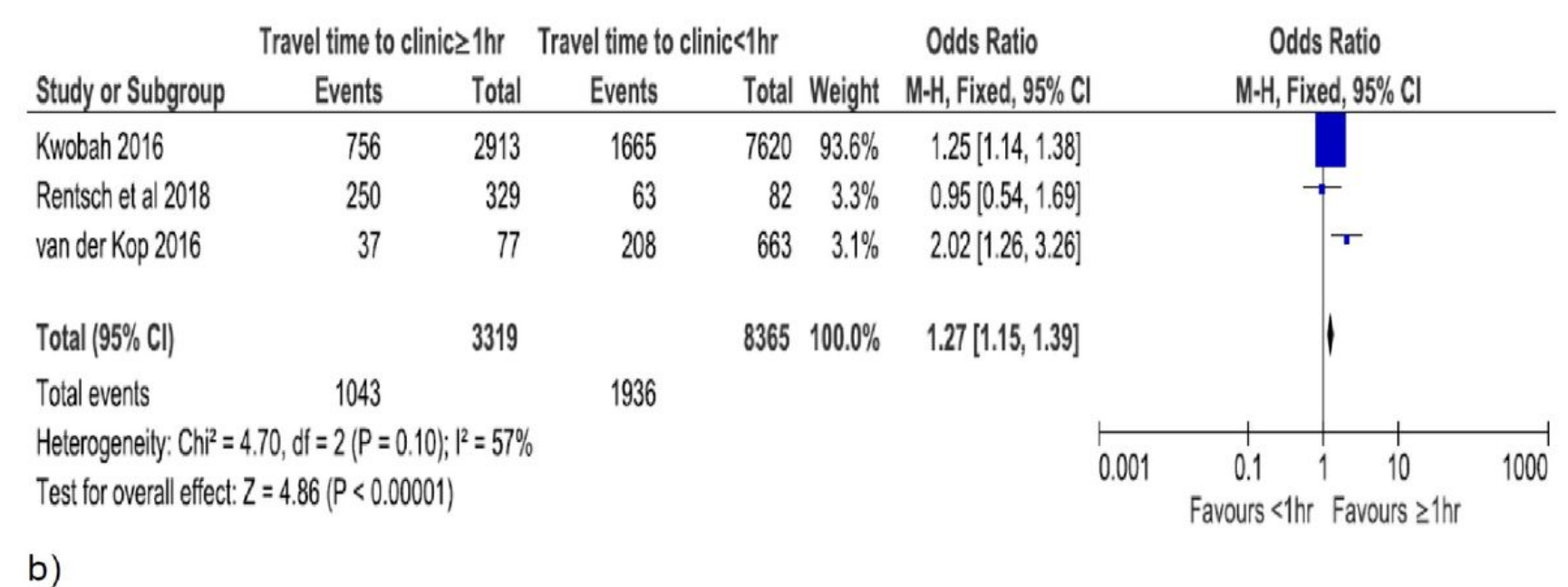

Figure 3

Forest plot of associations between late presentation for care and employment (a), and travel time to a clinic (b). Higher likelihood of late presentation for care in employed people and people who were travelling for more than an hour to a clinic. 


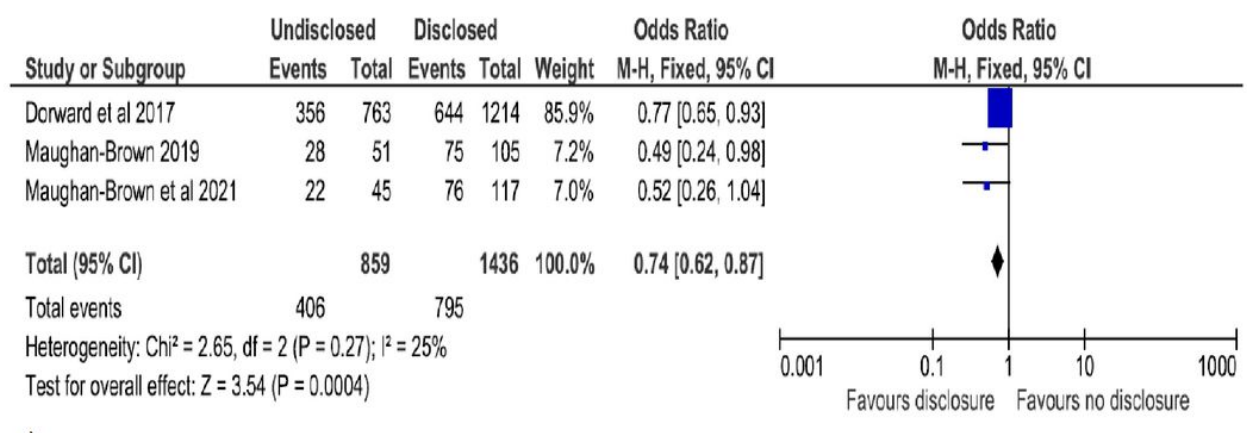

a)

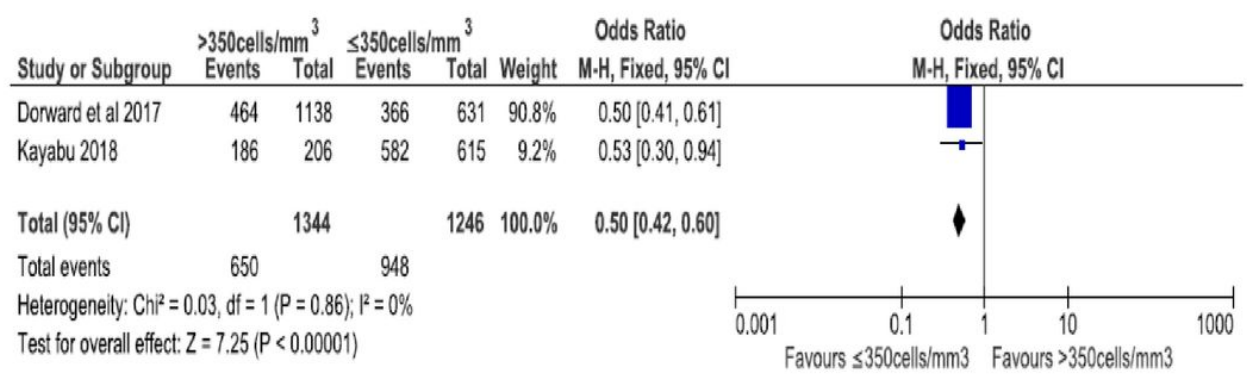

b)

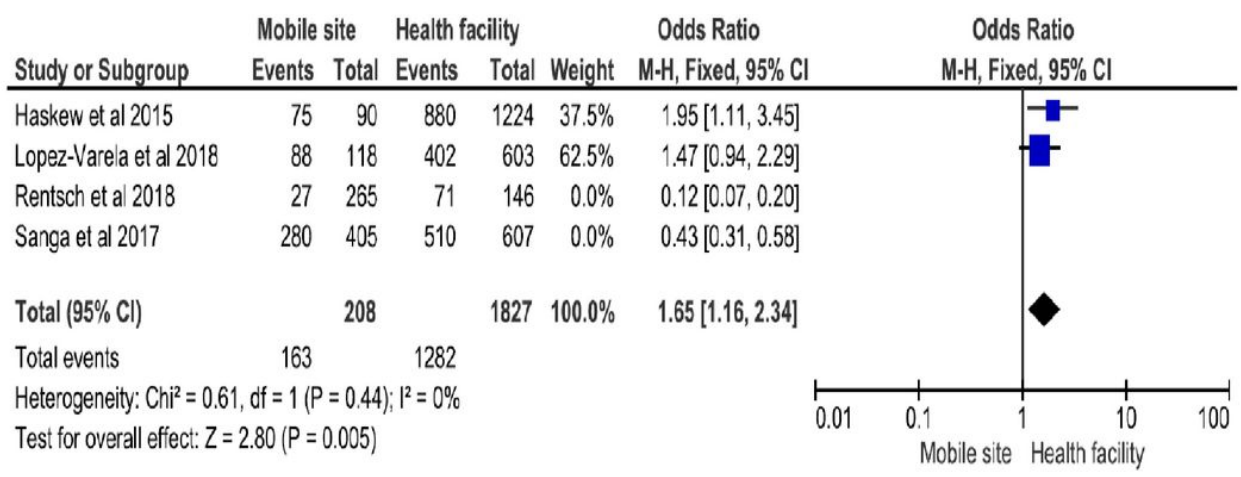

c)

\section{Figure 4}

Forest plot of associations between linkage to care and HIV status disclosure (a), baseline CD4 count (b) and testing modality (c). People who were unable to disclose their HIV status, had a higher CD4 count (CD4 count $>350$ cells $/ \mathrm{mm}^{3}$ ) and those who were diagnosed through community-based approaches were less likely to be linked to care.

\section{Supplementary Files}

This is a list of supplementary files associated with this preprint. Click to download.

- Additionalfile1txt.docx

- Additionalfile2pdf.pdf

- Additionalfile3pdf.pdf

- Additionalfile4txt.docx

- Additionalfile5txt.docx 